\title{
Melanocyte-like cells in the heart and pulmonary veins contribute to atrial arrhythmia triggers
}

\author{
Mark D. Levin, ${ }^{1,2}$ Min Min Lu, ${ }^{1}$ Nataliya B. Petrenko, ${ }^{1}$ Brian J. Hawkins, ${ }^{3}$ Tara H. Gupta, ${ }^{1}$ \\ Deborah Lang, ${ }^{1}$ Peter T. Buckley, ${ }^{4}$ Jeanine Jochems, ${ }^{4}$ Fang Liu, ${ }^{1}$ Christopher F. Spurney, ${ }^{5}$ \\ Li J. Yuan, ${ }^{1}$ Jason T. Jacobson, ${ }^{1}$ Christopher B. Brown, ${ }^{1}$ Li Huang, ${ }^{1}$ Friedrich Beermann, ${ }^{6}$ \\ Kenneth B. Margulies,,$^{1,7}$ Muniswamy Madesh, ${ }^{3}$ James H. Eberwine, ${ }^{4}$ \\ Jonathan A. Epstein, 1,2,7,8 and Vickas V. Patel ${ }^{1,7}$

\begin{abstract}
${ }^{1}$ Penn Cardiovascular Institute and University of Pennsylvania, Philadelphia, Pennsylvania, USA. 2 Division of Cardiology, Children's Hospital of Philadelphia, Philadelphia, Pennsylvania, USA. ${ }^{3}$ Institute for Environmental Medicine and ${ }^{4}$ Department of Pharmacology and Department of Psychiatry, University of Pennsylvania, Philadelphia, Pennsylvania, USA. ${ }^{5}$ Children's National Medical Center, Washington, DC, USA.

${ }^{6}$ Swiss Institute for Experimental Cancer Research (ISREC), Lausanne, Switzerland. ${ }^{7}$ Division of Cardiovascular Diseases and ${ }^{8}$ Department of Cell and Developmental Biology, University of Pennsylvania, Philadelphia, Pennsylvania, USA.
\end{abstract}

\begin{abstract}
Atrial fibrillation is the most common clinical cardiac arrhythmia. It is often initiated by ectopic beats arising from the pulmonary veins and atrium, but the source and mechanism of these beats remains unclear. The melanin synthesis enzyme dopachrome tautomerase (DCT) is involved in intracellular calcium and reactive species regulation in melanocytes. Given that dysregulation of intracellular calcium and reactive species has been described in patients with atrial fibrillation, we investigated the role of DCT in this process. Here, we characterize a unique DCT-expressing cell population within murine and human hearts that populated the pulmonary veins, atria, and atrioventricular canal. Expression profiling demonstrated that this population expressed adrenergic and muscarinic receptors and displayed transcriptional profiles distinct from dermal melanocytes. Adult mice lacking DCT displayed normal cardiac development but an increased susceptibility to atrial arrhythmias. Cultured primary cardiac melanocyte-like cells were excitable, and those lacking DCT displayed prolonged repolarization with early afterdepolarizations. Furthermore, mice with mutations in the tyrosine kinase receptor Kit lacked cardiac melanocyte-like cells and did not develop atrial arrhythmias in the absence of DCT. These data suggest that dysfunction of melanocyte-like cells in the atrium and pulmonary veins may contribute to atrial arrhythmias.
\end{abstract}

\section{Introduction}

Atrial fibrillation (AF) is the most common cardiac arrhythmia and is associated with significant morbidity (1-4). Most individuals with AF have underlying cardiac disease, but approximately $30 \%-45 \%$ with paroxysmal AF and $20 \%-25 \%$ with persistent AF are younger patients with no cardiac abnormalities $(5,6)$. Haissaguerre et al. identified ectopic beats arising from the pulmonary veins (PVs) as initiators or arrhythmogenic triggers of $\mathrm{AF}$ (7) which led to PV isolation as an effective, empiric therapy for drug-refractory AF. However, PV isolation is associated with complications and risks, including PV reconnection, which reduces its efficacy (8-10). On the other hand, pharmacologic anti-arrhythmic therapy for AF is often ineffective and associated with burdensome side effects (11-13).

While most investigations to date have focused on the contribution of PV myocytes to AF triggers, some evidence supports the existence of nonmyocardial cells within PVs, which may also contribute to these triggers. Recently, interstitial Cajal-like cells have been identified within human PVs $(14,15)$. However, the direct contribution of such cells to atrial arrhythmogenesis has not been demonstrated. Still, the implications of identifying a unique cell population that may contribute to atrial arrhythmias are signifi-

Conflict of interest: The authors have declared that no conflict of interest exists. Citation for this article: J. Clin. Invest. 119:3420-3436 (2009). doi:10.1172/JCI39109. cant, as they may unmask a previously unknown source or mechanism of arrhythmogenesis. In addition to descriptions of new cell types that may contribute to atrial arrhythmias, emerging evidence supports the contribution of atrial ectopy outside the thoracic veins to atrial arrhythmias $(16,17)$. Since atrial myocytes do not possess the same cellular electrophysiological properties as those found in PV myocytes, the theories proposed to explain the initiation of PV ectopy are unlikely to account for extrapulmonary vein foci. Therefore, the existence of a distinct cell population that may contribute to atrial triggers from the PVs and extrapulmonary foci may help explain this apparent inconsistency.

Pigmented cells within the murine heart have been observed previously (18-21), though their function remains unknown. Interestingly, dermal melanocytes and melanoma lines do express voltage-dependent currents $(22,23)$ and under conditions of increased oxidative stress some ionic currents are modified to promote cellular excitability (24-26). In the skin, reactive intermediaries such as 5,6-dihydroxyindole (DHI) (27) are formed in the pheomelanin synthesis pathway. On the other hand, 5,6-dihydroxyindole-2-carboxylic acid (DHICA), which is thought to be less reactive than DHI, is formed in the eumelanin synthesis pathway, diminishing the formation of reactive species (28). The melanin synthesis enzyme dopachrome tautomerase (Dct) contributes to, but is not required for, melanin synthesis in dermal melanocytes by catalyzing the conversion of L-dopachrome to DHICA (29). In the 

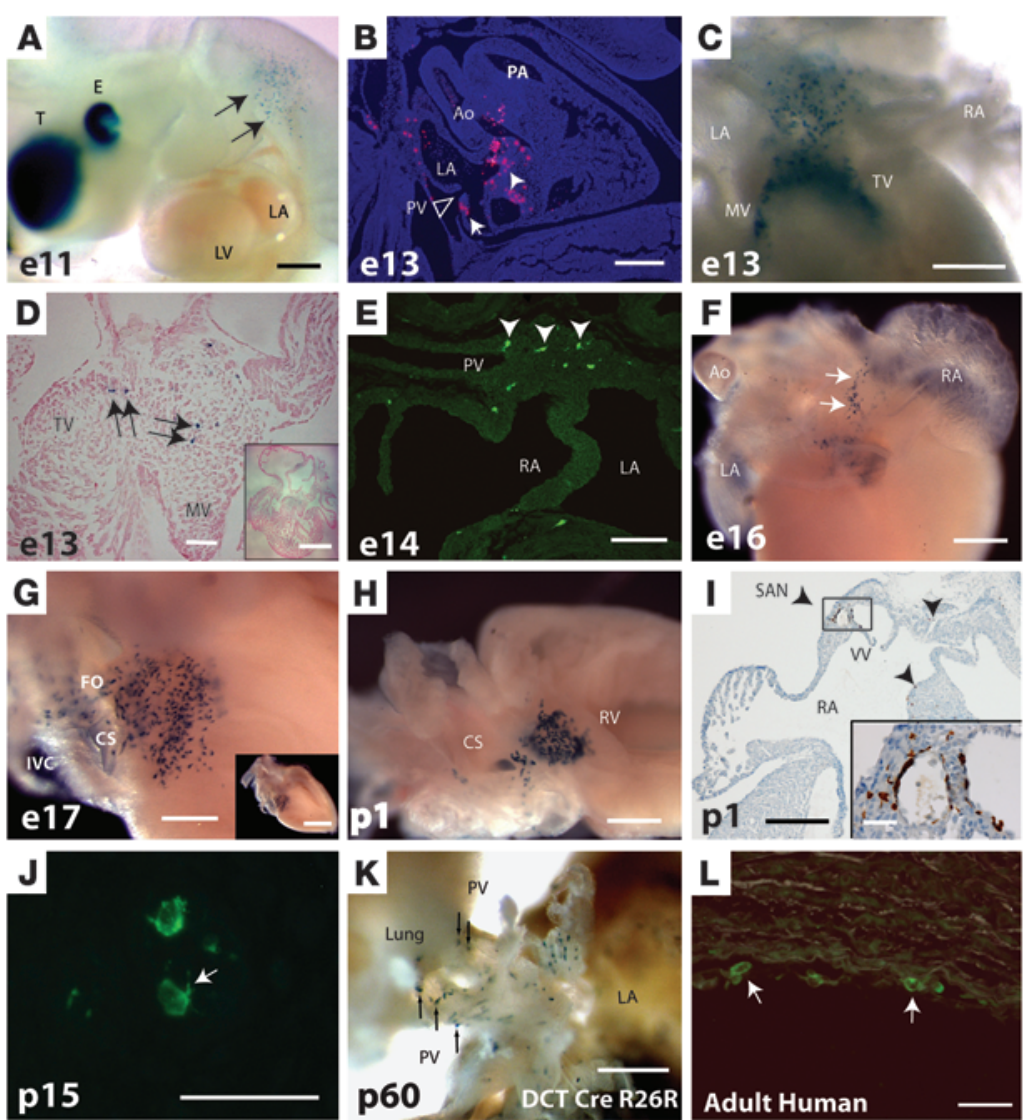

\section{Figure 1}

Dct-expressing cells populate the heart. (A) X-gal staining of an E11.5 Dct-LacZ embryo demonstrated staining near pharyngeal arches (arrows), developing telencephalon ( $T$ ), and eye (E). (B) In situ hybridization of an E13.5 heart showed Dct expression (filled arrows) around a PV os (open arrowhead). (C) X-gal staining of an E13.5 Dct-LacZ heart in the posterior atrium and endocardial cushions. (D) X-gal staining of an E13.5 Dct-LacZ heart in the septal leaflet valve primordia. Inset scale bar: $500 \mu \mathrm{m}$. (E) Immunofluorescence of Dct-positive cells (arrowheads) within the PVs. (F) $\mathrm{X}$-gal staining in an E16.5 Dct-LacZ heart in the posterior atrium (arrows). ( $\mathbf{G}$ and $\mathbf{H}) \mathbf{X}$-gal staining in a DctLacZ heart along the right atrial septum above the valve annulus at E17.5 (G; inset scale bar: $500 \mu \mathrm{m})$ and P1 (H). (I) Immunofluorescence showed Dct-positive cells lining the SAN artery epithelium, the tricuspid valve, and the mitral valve. Inset (scale bar: $100 \mu \mathrm{m}$ ) shows boxed region. (J) Immunofluorescence of Dct-positive cells (arrow) in the tricuspid valve of a 15-day-old mouse. (K) Adult mouse (P60) resulting from crossing a Dct$\mathrm{Cre}^{+/-}$and $\mathrm{R} 26 \mathrm{R}$ mouse demonstrated LacZ-positive cells (arrows) within the PVs and atria. (L) Dct-positive cells detected by immunofluorescence (arrows) on the endothelium of explanted human PV. Scale bars: 500 $\mu \mathrm{m}(\mathbf{A}-\mathbf{C}, \mathbf{F}, \mathbf{H}, \mathbf{I}, \mathbf{K}) ; 100 \mu \mathrm{m}(\mathbf{D}, \mathbf{E}, \mathbf{G})$; and $50 \mu \mathrm{m}(\mathbf{J}$ and L). LA, left atrium; Ao, aorta; PA, pulmonary artery; $\mathrm{MV}$, mitral valve; TV, tricuspid valve; RA, right atrium; IVC, inferior vena cava; FO, foramen ovale; CS, coronary sinus; SAN, sinoatrial node; $\mathrm{VV}$, venous valve. absence of Dct, there is decreased DHICA formation with concomitant DHI build up, which promotes the accumulation of reactive species $(30,31)$. Furthermore, Dct is important for intracellular calcium regulation; in fact, eumelanin binds calcium with an affinity similar to calmodulin (32). Given that dysregulation of calcium and reactive species have been described in patients with $\mathrm{AF}(33)$, and the fact that Det is involved in both calcium handling and reactive species generation, we sought to investigate the role of Dct and Dct-expressing cells in atrial arrhythmogenesis.

In the present study, we characterized Dct-expressing cells in the murine and human heart. Single-cell transcriptional profiling showed that murine Dct-expressing cells in the heart more closely resemble atrial myocytes than dermal melanocytes. Mice lacking functional DCT retained melanocyte-like cells in the heart and were susceptible to atrial arrhythmias. By contrast, animals lacking melanocyte-like cells in the heart failed to demonstrate atrial arrhythmias, even if they also lacked Dct. Isolated cardiac melanocytes were excitable, with similar action potentials to atrial myocytes. However, in the absence of Dct, cardiac melanocytes displayed prolonged repolarization with early afterdepolarizations and frequent calcium oscillations. Dct-positive cells in the murine atrium expressed adrenergic and muscarinic receptors and appeared to be innervated by autonomic nerves. Furthermore, treatment with muscarinic agonists resulted in fewer atrial arrhythmia episodes in mice that lacked cardiac melanocyte-like cells than in littermates that retained cardiac melanocytes, suggesting that the presence of these cells promotes arrhythmogenesis. $\beta$-Adrenergic antagonists reduced atrial arrhythmias to a larger extent in mice with cardiac melanocytes, further demonstrating the impor- tance of autonomic regulation of this cell population. Treatment of mice lacking Dct with antioxidants also significantly reduced atrial arrhythmias. These findings support a potential connection between Dct-expressing cells, the clinical syndrome of atrial ectopy initiating $\mathrm{AF}$, autonomic dysregulation, and oxidative stress.

\section{Results}

Melanocyte-like cells are present in the murine and buman PVs. We examined Dct expression in the heart by in situ hybridization, immunohistochemistry, and $\beta$-galactosidase staining in DctLacZ mice (34) during murine embryogenesis and found strong

\section{Table 1}

Distribution of Dct-expressing cells in P1 murine heart

\section{Location}

Right atrium

Left atrium

Atrial septum

Tricuspid annulus

Mitral annulus

Pulmonary valve

Aortic valve

PVs

Ventricular myocardium

Total cell count

\section{Cell number}

$425.3 \pm 62.4$

$202.8 \pm 55.0$

$287.1 \pm 75.5$

$894.2 \pm 24.2$

$805.7 \pm 86.3$

$152.0 \pm 44.6$

$315.3 \pm 20.2$

$266.6 \pm 49.6$

0 

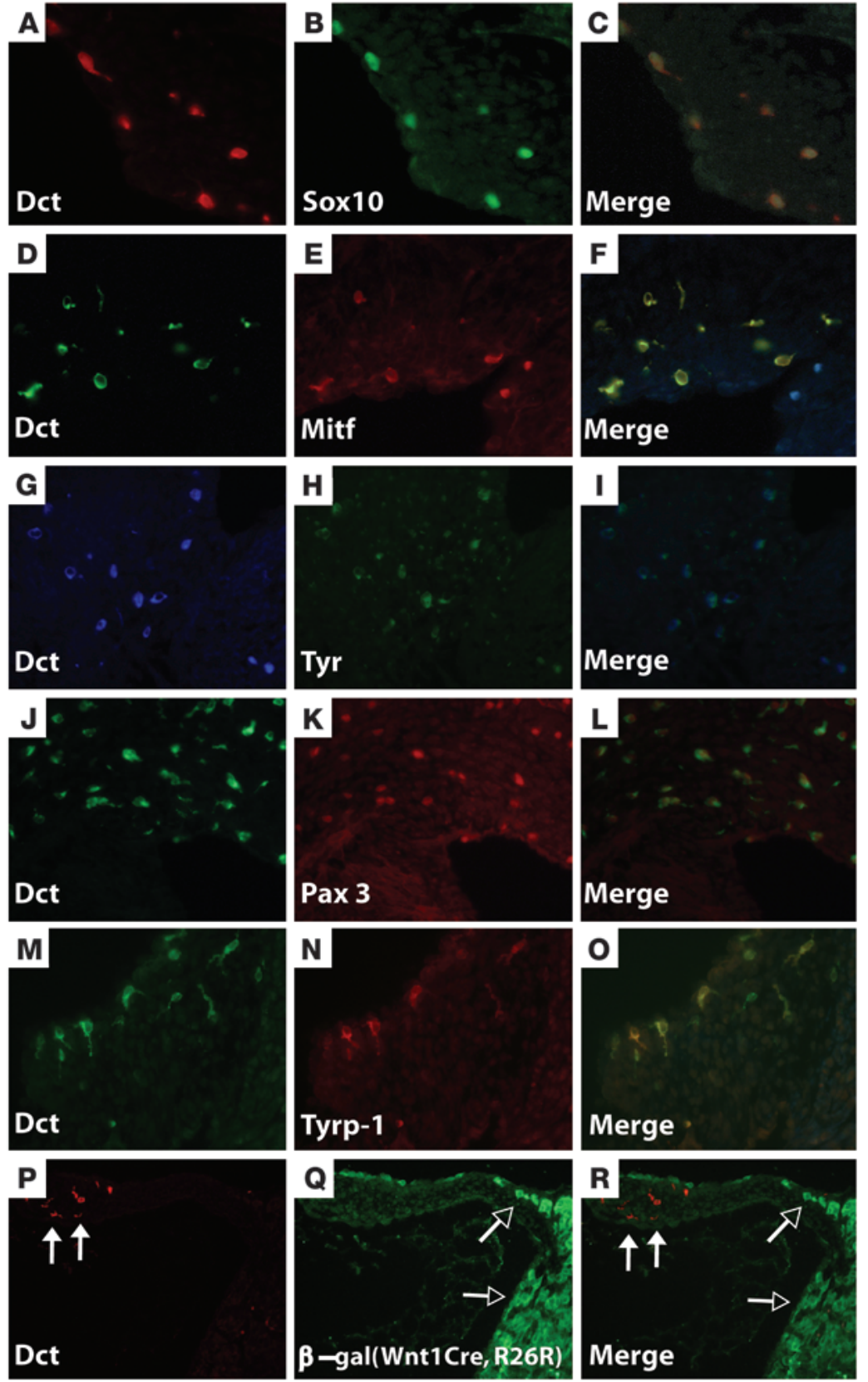

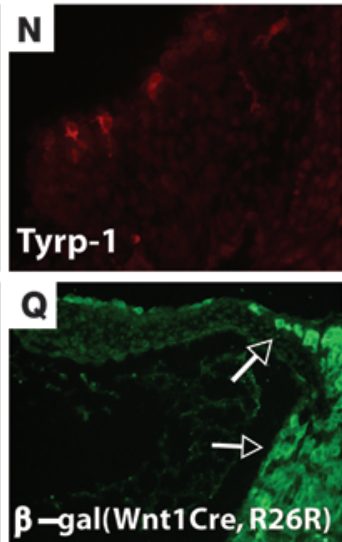

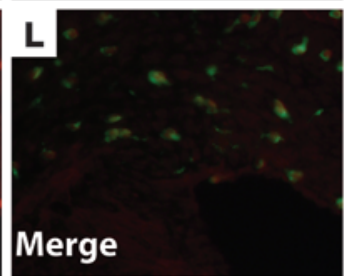
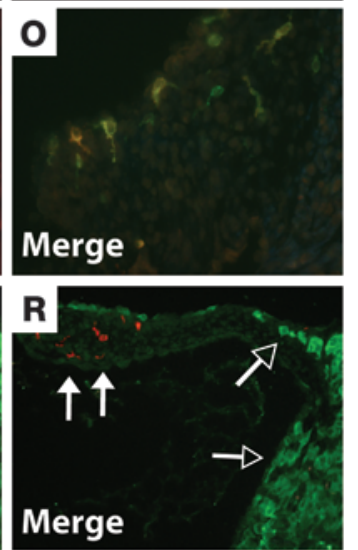

\section{Figure 2}

Dct-expressing cells in the atrium express markers of the melanoblast lineage. (A-0) Sections from E17.5 hearts co-stained by immunofluorescence for Dct $(\mathbf{A}$, D, G, J, and M), Sox10 (B), Mitf (E), Tyr (H), Pax3 $(\mathbf{K})$, and Tyrp-1 $(\mathbf{N})$, respectively. Merged images for Dct and each individual marker are shown (C, F, I, L, and $\mathbf{O})$. (P-R) Section through the anterior leaflet of the pulmonary valve of an $\mathrm{E} 17.5 \mathrm{Wnt1} \mathrm{Cre}, \mathrm{R} 26 \mathrm{R}$ heart stained for Dct (arrows, P) and $\beta$-galactosidase (open arrows, $\mathbf{Q}$ ). No overlap of staining was seen in merge (R). Original magnification, $\times 400(\mathbf{A}-\mathbf{0}) ; \times 100(\mathbf{P}-\mathbf{R})$. expression in mid- to late-gestation hearts. Through E11.5, Dct-expressing cells were not identified in the heart, unlike previously described cardiac neural crest cells (Figure 1A) $(35,36)$. By E13.5, Dct-expressing cells were evident in the PVs, posterior atrium, and septal leaflets of the atrioventricular valves (Figure 1, B-D). Between E14.5 and E16.5, Dct-positive cells were present in the posterior atrium and atrial-PV anastomoses (Figure 1, $\mathrm{E}$ and F). By late gestation, Dct-expressing cells were prominent near the region of, but not specifically within, the compact atrioventricular node (Figure 1, G-I), as well as around the region of the sinoatrial node (Figure $1 \mathrm{I}$ and Table 1 ). Thereafter, punctate expression of these cells within the heart and PVs was retained from birth to adulthood (Figure 1, I-K). We also identified Dctpositive cells within the PVs of all 8 human postmortem samples examined (Figure 1L). Interestingly, pigmentation of these cells in humans was not evident. The absence of tyrosinase related protein-1 (Tyrp-1; data not shown) may explain why these cells are not pigmented, since Tyrp-1, but not Dct, denotes melanocyte differentiation with pigment expression.

Dct-positive cells express melanoblast markers but not those of cardiomyocytes, fibroblasts, or neurons. In the mouse embryo, Dct-positive cells in the heart expressed markers of the melanoblast lineage, including Sox10, Mitf, and tyrosinase (Tyr). At a later time point (E17.5), Tyrp1 and Pax3 were also expressed (Figure 2, A-O). These cells appeared to be morphologically distinct from cardiomyocytes (Figure 2, A, J, and M). Ultrastructural analysis of Dct-expressing cells showed numerous caveolae along the plasma membrane and a subset of cells that contained mature melanosomes (Figure 3, A-D). 

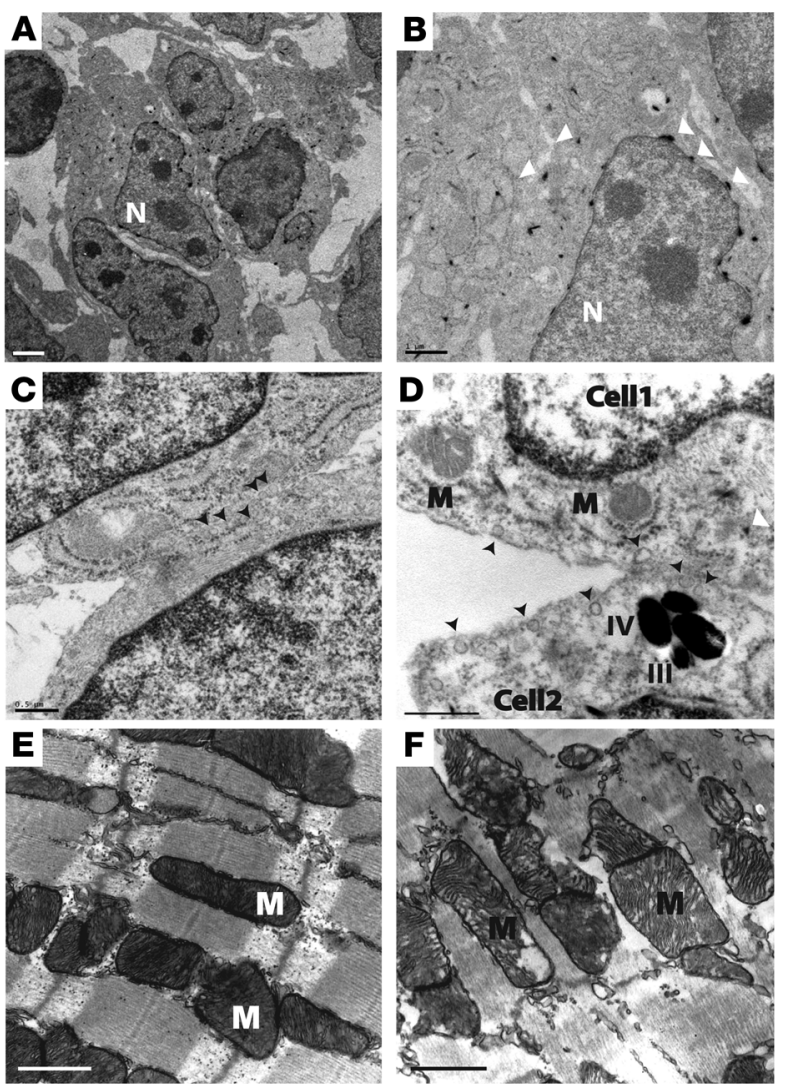

Expression of fibronectin, neurofilament, tyrosine hydroxylase, $\alpha$-actin, MF20, smooth muscle actin, and Islet 1 was not observed in Dct-expressing cells distinguishing these cells from fibroblasts, neurons, myocytes, smooth muscle, and secondary heart field cells, respectively (Supplemental Figure 1; supplemental material available online with this article; doi:10.1172/JCI39109DS1) (37).

Murine cardiac melanocyte-like cells are distinct from other cardiac neural crest lineages. Most, but not all, melanocytes are derived from multipotent neural crest precursors that arise in the dorsal neural tube, where they express Wnt1 and Pax3 $(38,39)$. To fate-map neural crest cells, we crossed Wnt1Cre (36) transgenic and Pax3Cre knockin (40) mice with R26R LacZ reporter mice (41) and examined E16.5 (Pax3Cre and Wnt1Cre) and P1 (Wnt1Cre) hearts with antibodies that recognize DCT and $\beta$-galactosidase (Figure 2, P-R). Surprisingly, fate-mapped Pax3Cre and Wnt1Cre cells did not express Dct. Moreover, we have examined hundreds of mid-gestation embryonic hearts derived from Wnt1/Pax3Cre, $R 26 R$ crosses and we have never observed LacZ-expressing cells in the atrioventricular canal where Dct expression was prominent, although Wnt1/Pax3Cre-derived cells contribute to septation of the outflow tract and the great vessels (our unpublished observations). However, by E17.5, Dct-expressing cells began to co-express Pax3 (Figure 2, J-L). Based on these findings, we concluded that Dct-expressing cells in the heart represent a distinct population from Wnt $1 /$ Pax3 expressing precursors that orchestrate outflow tract septation, although they activate Pax3 expression during late gestation. Thus, these cells either may arise from what we believe is a newly identified subpopulation of neural crest precursors that fail to express Wnt1 or Pax3 at early time points and for which we

\section{Figure 3}

Ultrastructural analysis of Dct-expressing cardiac cells. (A) Low-power and (B) high-power transmission electron microscopy demonstrated association between 4 Dct-LacZ-expressing cells. White arrowheads indicate electron-dense $\mathrm{X}$-gal precipitate in the cytoplasm and perinuclear area. $\mathbf{N}$ denotes the same nucleus in both $\mathbf{A}$ and $\mathbf{B}$ (scale bars: $2 \mu \mathrm{m}$ and $1 \mu \mathrm{m}$, respectively). (C and D) High-power transmission electron microscopy of 2 Dct-expressing cells. Cells in $\mathbf{C}$ contained no melanosomes, while Cell2 in $\mathbf{D}$ contained type III and type IV melanosomes. Cell1 contained X-gal precipitate (white arrowhead). Black arrowheads in $\mathbf{C}$ and $\mathbf{D}$ denote caveolae. Scale bars: $500 \mathrm{~nm}$. ( $E$ and $\mathbf{F}$ ) High-power transmission electron microscopy of mitochondria in the atrial myocardium of a $D c t^{+/-}$mouse (E) and a $D c t^{--}$mouse (F). Note that some mitochondria appear slightly enlarged, with less densely packed and disorganized matrices in the absence of Dct. Scale bars: $500 \mathrm{~nm}$. N, nucleus; M, mitochondria; III, type 3 melanosome; IV, type 4 melanosome.

do not presently know of an available genetic marker, or they may arise from a non-neural crest-derived cell lineage.

Transcriptional profiling suggests cardiac melanocyte-like cells are distinct from dermal melanocytes and atrial myocytes. We performed single-cell isolation and transcriptional profiling of Dct-expressing cells in the heart in order to define a gene expression signature and for comparison to related cell types. In parallel, we profiled atrial myocytes and dermal melanocytes (Figure 4) (42). Interestingly, cluster analysis of global gene expression suggested Dctexpressing cells are more closely related to atrial myocytes than to dermal melanocytes. Both cell types express similar calciumhandling proteins (such as phospholamban and ryanodine receptor, type 2) and some voltage-gated ion channels (for example the pore-forming subunit of L-type calcium channels and cardiac voltage-dependent sodium channels; Supplemental Tables 1-3). However, Dct-positive cells in the heart lacked significant expression of some signature cardiomyocyte genes, such as cardiac actin and troponins (Table 2 and Supplemental Tables 1-3). Thus, Dctexpressing cells in the heart can be molecularly distinguished from atrial myocytes and dermal melanocytes.

Murine melanocyte-like cells are present in the heart despite the absence of Dct. To examine the function of Dct-expressing cells in the heart, we utilized Dct-Cre mice that produce no functional DCT (43). $D c t^{+/-}$mice appear phenotypically normal, while $D c t^{-1-}$ mice are viable and display reduced pigmentation. We generated $D c t^{-1-}$ mice that also carried the Dct-LacZ transgene to examine expression of $\beta$-galactosidase in $D c t^{+/+}$and $D c t^{/-}$embryos. $D c t-L a c Z$ was expressed normally in the hearts of $D c t /-$ embryos, suggesting that Dct expression is not required for migration or survival of melanocyte-like cells in the heart (Figure 5).

Dct ${ }^{-1}$ mice are susceptible to induced and spontaneous atrial arrbythmias in the absence of structural cardiac abnormalities. The location of Dctexpressing cells in the PVs, atrium, and atrioventricular annulus prompted us to investigate the contribution of Dct to cardiac electrical activity and conduction. We performed invasive electrophysiologic studies in mature $D c t^{--}$and $D c t^{+/-}$littermates. Atrial burst pacing induced 27 episodes of atrial arrhythmia in 9 of $11 \mathrm{Dct}^{-1-}$ mice (Figure 6A and Table 3). These episodes lasted $781 \pm 417$ milliseconds (range: 119-1529 ms), while the same protocol induced 2 episodes in 1 of 12 control mice (172 and $540 \mathrm{~ms}$ ). In addition, spontaneous episodes of atrial tachycardia were recorded in 2 of 4 conscious $\mathrm{Dct}^{-1}$ mice with implantable ambulatory monitors, while control littermates demonstrated no such activity (Figure 6B). Addi- 

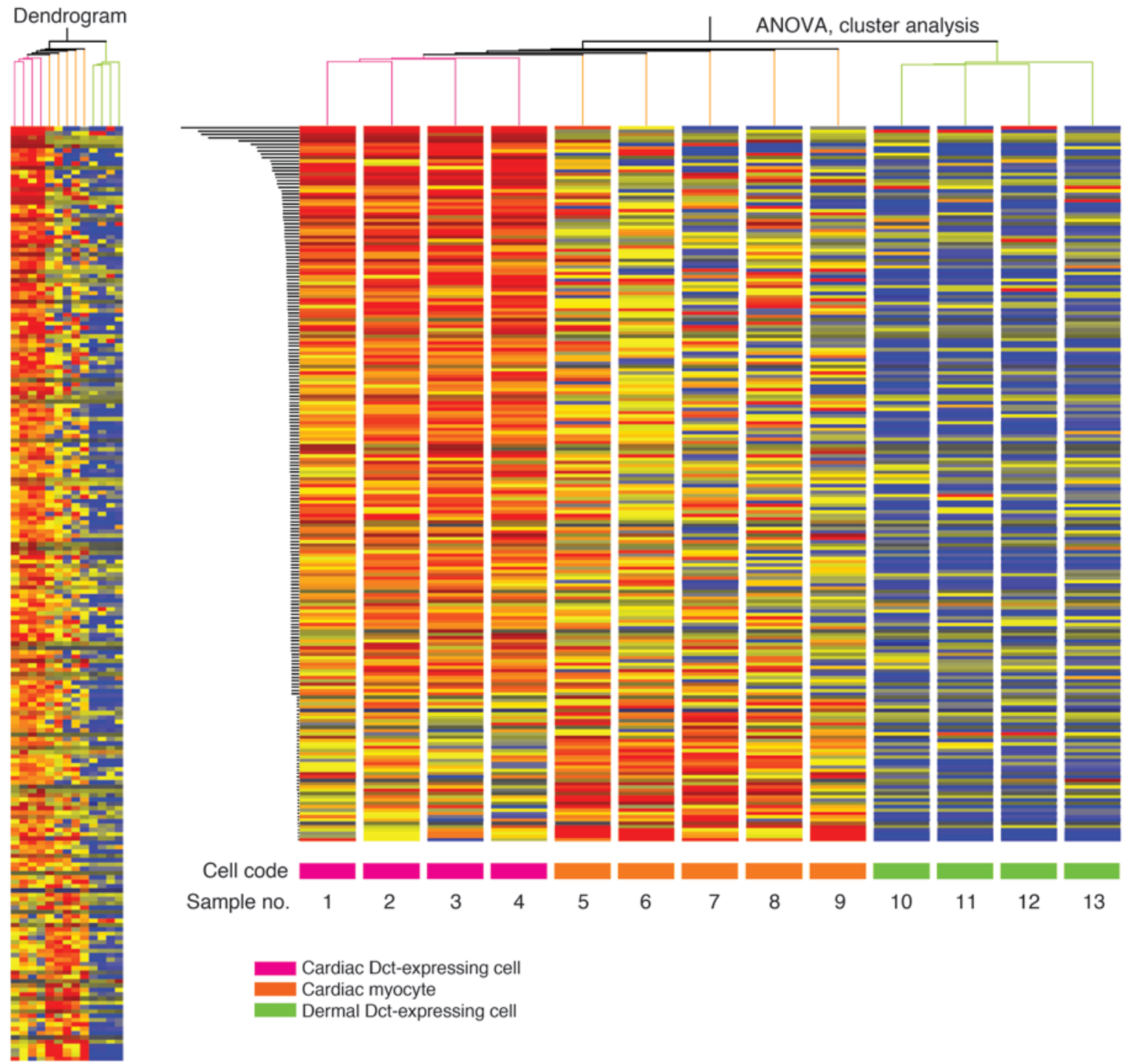

\section{Figure 4}

Hierarchical clustering and ANOVA of single-cell gene expression data. Each column represents expression data from a single cell from 1 of 3 classes: cardiac Dct-expressing cell (pink), atrial myocyte (orange), or dermal Dct-expressing cell (green). Expression analysis was performed on those transcripts that had 2-fold expression above or below the mean in each cell class. The cluster analysis depicted at top was subsequently performed after ANOVA demonstrated significant expression differences between each of the 3 cell classes. Fold changes are represented graphically, with red tiles demonstrating greater than 2-fold expression above the median, yellow representing median expression, and blue demonstrating expression 2-fold below the median. See Supplemental Table 3 for the identity of the genes analyzed. Dendrograms show correlation of gene expression profiles between samples. The length of the dendrogram branches connecting pairs of nodes represents the level of correlation between samples. Note that each cell class segregates to a discrete node, with the cardiac Dct-expressing cells sharing greater correlation with atrial myocytes than dermal Dct-expressing cells, confirming that each cellular class has a distinct signature.

tional invasive electrophysiological analysis revealed no differences in conduction intervals or refractory periods (Table 3 ). Consistent with these analyses, the surface ECG revealed no difference in baseline intervals or electrogram morphology (Figure 6C and Supplemental Table 4). Therefore, Dct/- mice show increased susceptibility to atrial arrhythmogenesis, unaccompanied by any other cardiac electrophysiological alteration.

To examine whether the atrial arrhythmias observed in the absence of Dct were related to alterations in atrial or ventricular structure, echocardiographic and histological analysis were per- formed in $D c t^{-/-}$and $D c t^{+/-}$mice. However, no structural or functional abnormalities were found in $D c t^{-1-}$ mice compared with control littermates (Figure 6D and Supplemental Table 5). In addition, myocardial interstitial fibrosis and alterations in myocyte structure were not observed in $D_{c t} /-$ mice compared with control littermates (data not shown). Therefore, it is unlikely that the atrial arrhythmias observed in $D c t^{-1-}$ mice resulted from primary derangements in atrial structure or function.

Presence of Dct-expressing cells in the heart is Kit dependent. To examine how Dct-expressing cells promote arrhythmogenesis, we utilized a 
Table 2

Expression of selected ion channel and calcium-handling transcripts in cardiac Dct-expressing cells

$\begin{array}{lc}\text { Symbol } & \text { GenBank ID } \\ \text { PIn } & \text { AK002622 } \\ \text { Cacna1c } & \text { NM_009781 } \\ \text { Atp2b1 } & \text { BI080417 } \\ \text { Ryr2 } & \text { NM_023868 } \\ \text { Gjc1 } & \text { NM_008122 } \\ \text { Atp2a2 } & \text { AA245637 } \\ \text { Clic4 } & \text { BB814844 } \\ \text { Vdac2 } & \text { BC003731 } \\ \text { Cav3 } & \text { NM_007617 } \\ \text { Kctd18 } & \text { BB257241 } \\ \text { Atp1a1 } & \text { BC025618 } \\ \text { Kcmf1 } & \text { BG071725 } \\ \text { Clic4 } & \text { BB398988 } \\ \text { Scn5a } & \text { BB516098 } \\ \text { Kcnk3 } & \text { BF467278 } \\ \text { Kcnj1 } & \text { NM_019659 }\end{array}$

$\begin{array}{cc}\text { Description } & \text { Fold change } \\ \text { Phospholamban } & 5.93 \\ \text { Calcium channel, voltage-dependent, L-type, } \alpha 1 \mathrm{C} \text { subunit } & 2.49 \\ \text { ATPase, } \mathrm{Ca}^{++} \text {transporting, plasma membrane 1 } & 2.67 \\ \text { Ryanodine receptor 2, cardiac } & 2.31 \\ \text { Gap junction protein, } \gamma 1 & 2.30 \\ \text { ATPase, Ca++ transporting, cardiac muscle 2 } & 1.88 \\ \text { Chloride intracellular channel 4 } & 1.82 \\ \text { Voltage-dependent anion channel 2 } & 1.74 \\ \text { Caveolin 3 } & 1.60 \\ \text { Potassium channel tetramerization domain } & 1.58 \\ \text { ATPase, Na+/K+ transporting, } \alpha \text { 1 polypeptide } & 1.53 \\ \text { Potassium channel modulatory factor 1 } & 1.52 \\ \text { Chloride intracellular channel 4 } & 1.51 \\ \text { Sodium channel, voltage-gated, type V, } \alpha & 1.14 \\ \text { Potassium channel, subfamily K, member 3 } & 1.11 \\ \text { Potassium inwardly rectifying channel, subfamily J, member 1 } & 1.08\end{array}$

Single-cell transcriptional profiling was performed on atrial and dermal primary cultures of $D c t^{+/-}$mice. RNA was harvested from 5 different samples of cardiac Dct-expressing cells, dermal Dct-expressing cells, and atrial myocytes. Expression data were normalized to the mean of all transcripts assays for in each cell type and displayed as fold change above the norm of the transcripts assayed in atrial myocytes. The GeneSpring analysis program was used to identify those genes categorized as ion channel transcripts. The above table represents the identity of ion channel transcripts with greater than 1.0-fold expression above the norm within the ion channel category.

mouse model lacking Dct-expressing cells in the heart. Mice with mutations in the tyrosine kinase receptor Kit $(W /+, W v /+$, and $W / W v)$ possess pigmentation defects secondary to impaired migration of some, but not all, neural crest-derived cell lines $(44,45)$. Therefore, we examined hearts from Kit mutant mice to determine whether these mutations affect migration of Dct-expressing cells. Gross and microscopic examination of hearts from $W / W v$ mice and wild-type littermates confirmed the absence of Dct-expressing cells within mutant hearts (Figure 7). Furthermore, invasive electrophysiology studies in $W / W v$ mice and $D c t^{/-}, W / W v$ littermates demonstrated no differences in atrial refractory periods or induced atrial arrhythmias in $W / W v$ versus $D c t /, W / W v$ mice (Dct/-, W/Wv: 5 episodes, $178 \pm 112 \mathrm{~ms}$; $W / W v: 2$ episodes, $99 \mathrm{~ms}$, $125 \mathrm{~ms} ; P=$ NS; Table 3 ). Thus, the lack of atrial arrhythmias, in the absence of Dct-expressing cells on a $D c t^{-/}$background, further implicates these cells as a source of atrial arrhythmogenesis.

Murine cardiac Dct-positive cells express adrenergic and muscarinic receptors and interact with autonomic nerves. Given the robust evidence linking alterations in autonomic efflux to the onset of PV ectopy and clinical AF (46-48), we sought evidence that Dct-expressing cells within the heart may be regulated by the autonomic nervous system. In the skin, dermal melanocytes are influenced by both sympathetic and parasympathetic input (49). Dctpositive cells express $\beta 1$-adrenergic, $\alpha 1$-adrenergic, and M3-muscarinic receptors (Figure 8, A-I), but not M1-muscarinic, M2-muscarinic, or $\beta 2$-adrenergic receptors (data not shown). Additionally, costaining against tyrosine hydroxylase and DCT revealed sympathetic nerve terminals abutting Dct-positive cells in the murine atrium (Figure 8, J-L). Costaining against choline acetyltransferase and DCT similarly revealed cholinergic nerves abutting Dct-positive cells (Figure 8, M-O). In addition, murine Dct-positive cells themselves express choline acetyltransferase. These data suggest a model whereby Dctexpressing cells in the murine atrium respond to autonomic efflux, which could contribute to arrhythmias.

Cardiac melanocytes influence autonomic effects upon atrial arrhythmogenesis. The fact that murine cardiac melanocytes express muscarinic and adrenergic receptors, and that they appear to interact with autonomic nerves, suggests these cells are influenced by the autonomic nervous system. To obtain direct evidence that autonomic influences upon cardiac melanocytes contribute to atrial arrhythmias, we performed invasive electrophysiology studies in wild-type mice and Kit mutant mice that lacked cardiac melanocytes. Since

\section{Figure 5}

Cardiac melanocyte-like cells persist in the heart in the absence of Dct. Hearts derived from $D c t^{+/-}(\mathbf{A}$ and $\mathbf{C})$ or $D c t^{-1}(\mathbf{B}$ and $\mathbf{D})$ mice that also carried the Dct-LacZ transgene were stained with X-gal. Anterior (A and $\mathbf{B}$ ) and posterior (C and $\mathbf{D}$ ) views are shown, with labeled cells seen in a similar pattern in $D c t^{+/-}$and $D c t^{--}$(filled arrows). Insets in C and $\mathbf{D}$ show the posterior atrial wall, where labeled cells are evident (arrows). Original magnification, $\times 40$ (A-D); ×100 (insets).
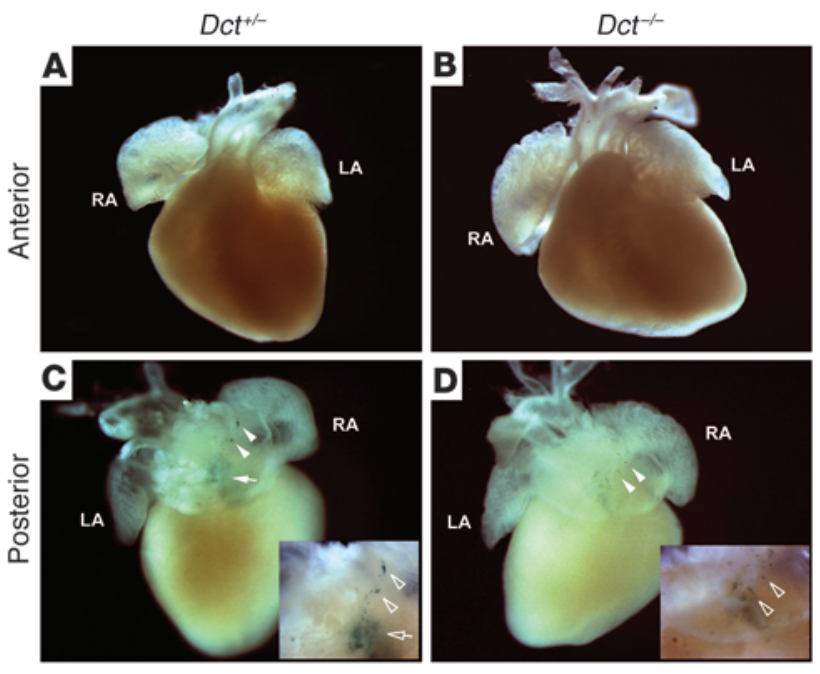
A

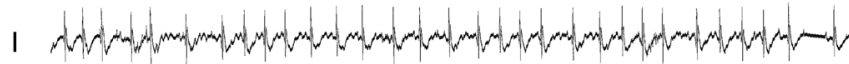

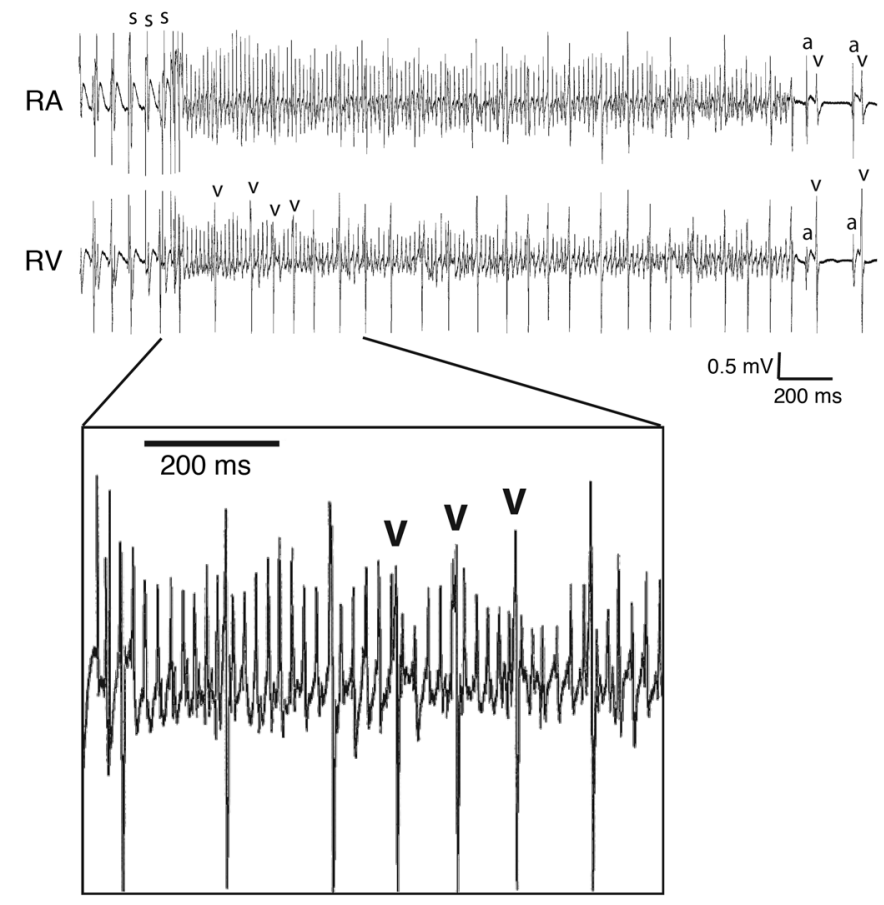

C

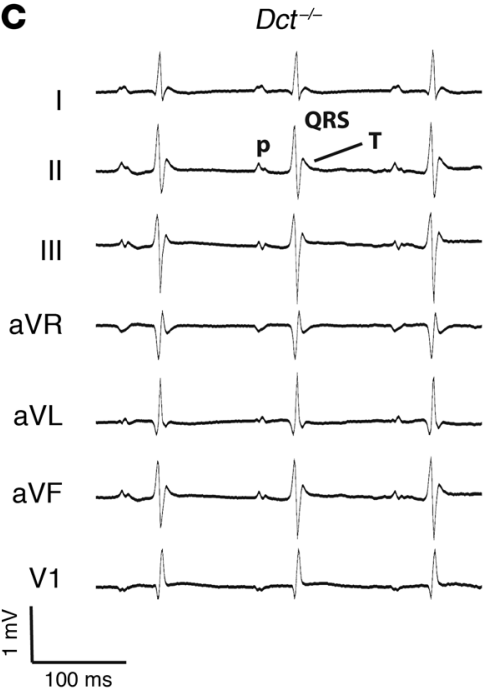

B

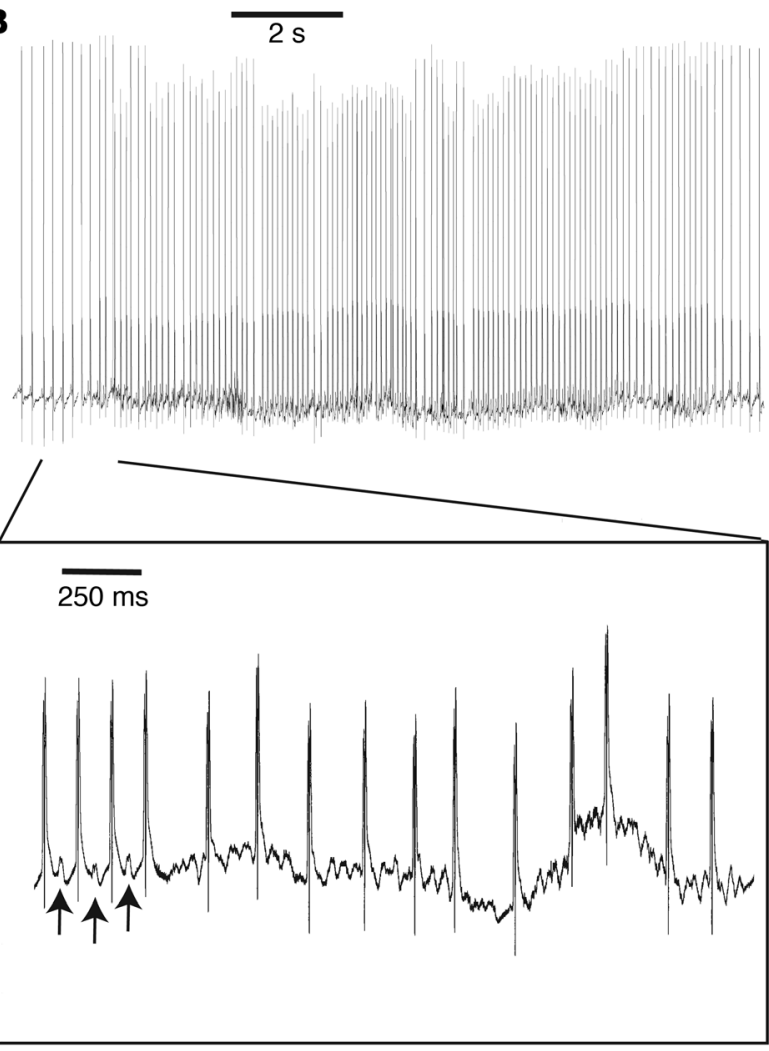

\section{D}
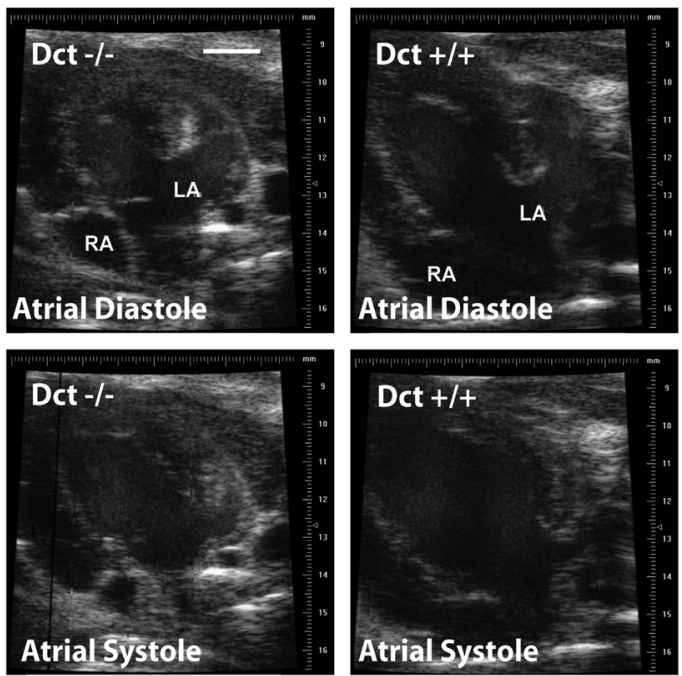

\section{Figure 6}

Dct $t^{-1}$ mice have inducible and spontaneous atrial arrhythmias with normal cardiac structure and function. (A) Recordings from ECG lead I (I), right atrium, and right ventricle show AF induced by burst stimulation (S) in a $D c t^{-1-}$ animal. Irregularly irregular intervals between ventricular ( $\mathrm{V}$ ) beats are denoted. Sinus beats are shown on termination of the episode with normal atrial (a) and ventricular electrograms. Inset demonstrates magnified view of denoted area. (B) Real-time telemetry recorded in an awake Dct ${ }^{-1}$ mouse with an implantable monitor demonstrates spontaneous AF characterized by abrupt onset of a rapid irregularly irregular rhythm with no discrete $p$-waves. The inset shows a faster time scale of a few beats of sinus rhythm (arrows), followed by the onset of AF. (C) Surface ECGs from $\mathrm{Dct}^{-1}$ and $\mathrm{Dct}^{+/-}$littermate mice demonstrating normal ECG morphologies. (D) Two-dimensional echocardiographic imaging from a 4-chamber view demonstrating no qualitative difference in atrial dimensions during atrial systole or atrial diastole in $\mathrm{Cct}^{-1-}$ and $D c t^{+/+}$littermate mice. Scale bar: $2 \mathrm{~mm}$. 
Table 3

Baseline invasive electrophysiology intervals

\begin{tabular}{|c|c|c|c|c|}
\hline Parameter & $\operatorname{Dct}^{-/-}(n=11)$ & $\operatorname{Dct}^{+-}(n=12)$ & $W / W v(n=10)$ & $D c t^{--}, W / W v(n=10)$ \\
\hline $\mathrm{AH}(\mathrm{ms})$ & $34.7 \pm 4.9$ & $30.8 \pm 6.4$ & $33.0 \pm 5.1$ & $35.1 \pm 5.8$ \\
\hline $\mathrm{H}_{d}(\mathrm{~ms})$ & $4.1 \pm 1.3$ & $4.3 \pm 1.1$ & $4.0 \pm 1.4$ & $4.2 \pm 1.0$ \\
\hline $\mathrm{HV}$ (ms) & $11.3 \pm 2.3$ & $11.1 \pm 2.7$ & $10.8 \pm 2.4$ & $11.0 \pm 2.1$ \\
\hline AVI (ms) & $49.0 \pm 6.5$ & $49.1 \pm 6.8$ & $48.7 \pm 6.4$ & $50.3 \pm 6.7$ \\
\hline $\mathrm{SNRT}_{120}(\mathrm{~ms})$ & $208.0 \pm 51.6$ & $230.1 \pm 74.2$ & $224.6 \pm 69.8$ & $238.2 \pm 67.6$ \\
\hline $\mathrm{SNRT}_{100}(\mathrm{~ms})$ & $200.3 \pm 68.3$ & $220.8 \pm 76.7$ & 209.4. \pm 58.9 & $222.7 \pm 66.1$ \\
\hline AVWCL (ms) & $94.5 \pm 6.9$ & $95.8 \pm 7.6$ & $99.4 \pm 7.4$ & $100 \pm 8.2$ \\
\hline $\operatorname{AVERP}_{120}(\mathrm{~ms})$ & $68.6 \pm 7.4$ & $67.5 \pm 9.9$ & 70.8. \pm 8.5 & $71.4 \pm 8.8$ \\
\hline $\mathrm{AERP}_{120}(\mathrm{~ms})$ & $39.5 \pm 7.3$ & $41.3 \pm 5.3$ & $43.8 \pm 5.7$ & $42.7 \pm 4.6$ \\
\hline $\mathrm{AERP}_{100}(\mathrm{~ms})$ & $38.2 \pm 5.6$ & $40.0 \pm 5.8$ & $44.6 \pm 6.2$ & $43.9 \pm 4.6$ \\
\hline $\operatorname{VERP}_{120}(\mathrm{~ms})$ & $33.2 \pm 11.5$ & $34.2 \pm 10.8$ & $35.8 \pm 9.5$ & $36.5 \pm 8.9$ \\
\hline VERP $_{100}(\mathrm{~ms})$ & $35.9 \pm 9.1$ & $32.9 \pm 11.6$ & $36.0 \pm 10.1$ & $36.8 \pm 9.7$ \\
\hline Episodes of AT & $27^{A, B, C}$ & $2^{D}$ & $2^{D}$ & $5^{\mathrm{D}}$ \\
\hline Episodes of VT & 7 & 10 & 8 & 9 \\
\hline ATCL (ms) & $32.2 \pm 7.8$ & 76.5 & 46.9 & $38.4 \pm 6.7$ \\
\hline AT duration (ms) & $781 \pm 417$ & 356 & 112 & $178 \pm 112^{A}$ \\
\hline $\operatorname{Age}(d)$ & $56.7 \pm 4.8$ & $58.4 \pm 6.4$ & $59.7 \pm 5.8$ & $62.0 \pm 7.9$ \\
\hline Weight (g) & $21.2 \pm 3.7$ & $21.4 \pm 2.8$ & $22.0 \pm 2.4$ & $21.8 \pm 2.6$ \\
\hline
\end{tabular}

AP $<0.05$ compared with $D c t^{+/-;}$B $P<0.05$ compared with $W / W v ;{ }^{C} P<0.05$ compared with $D c t^{--}, W / W v$; DP $<0.05$ compared with $\mathrm{Dct}^{-1}$. $\mathrm{AH}$, atrio-hisian interval; $\mathrm{H}_{\mathrm{d}}$, His duration; $\mathrm{HV}$, hisioventricular interval; $\mathrm{AVI}$, atrioventricular interval; $\mathrm{SNRT}_{120}$, sinus node recovery time at drive train of $120 \mathrm{~ms}$; AVWCL, atrioventricular Wenckebach block cycle length; $\mathrm{AVERP}_{120}$, atrioventricular effective refractory period at drive train of $120 \mathrm{~ms} ; \mathrm{AERP}_{120}$, atrial effective refractory period at drive train of $120 \mathrm{~ms}$; $\mathrm{VERP}_{120}$, ventricular effective refractory period at drive train of $120 \mathrm{~ms}$; AT, atrial tachycardia; VT, ventricular tachycardia; AT CL, atrial tachycardia cycle length. Data are presented as the mean $\pm \mathrm{SD}$ and tests of statistical difference were computed using 1-way ANOVA followed by Tukey post-hoc analysis. The numbers of arrhythmic episodes were assumed to have a Poisson distribution, and the KolmogorovSmirnov test was used to assess statistical significance between groups.

Kit mutant mice do not develop atrial arrhythmias (despite the presence or absence of $D c t$ ), we provoked atrial arrhythmia in these mice and their wild-type littermates using the long-acting muscarinic agonist carbamyl choline. Muscarinic stimulation promotes sustained atrial arrhythmias in mice with normal hearts (50). Carbamyl choline shortens atrial refractory periods through its action upon acetylcholine-activated inward rectifier currents in atrial myocytes, which induces the substrate to sustain atrial arrhythmias. These studies revealed that $W / W v$ mice had approximately $40 \%$ fewer induced atrial arrhythmias episodes than their wild-type littermates (W/Wv: 36 episodes in 6 of 8 mice lasting $27.8 \pm 2.9$ s; wildtype: 64 episodes in 7 of 8 mice lasting $29.1 \pm 3.5 \mathrm{~s}$; Table 4). There were no differences in the effects of these drugs upon conduction intervals or refractory periods between these 2 groups (Table 4). Administration of the $\beta$-adrenergic antagonist propranolol, in the presence of carbamyl choline, was about $25 \%$ more effective in reducing the number of induced atrial arrhythmia episodes in wildtype mice compared with $W / W v$ littermates (wild-type: 38 episodes in 6 of 8 mice, down from 64 episodes [ $41 \%$ reduction], lasting $24.1 \pm 3.2 \mathrm{~s} ; W / W v$ : 30 episodes in 7 of 8 mice, down from 36 episodes [ $17 \%$ reduction], lasting $23.6 \pm 2.6 \mathrm{~s}$; Table 5). These findings suggest that muscarinic and adrenergic regulation of cardiac melanocytes may affect the development of atrial arrhythmias.

Oxidant scavengers reduce atrial arrbythmias in Dct/- mice. Det has antioxidant effects in the skin (30), and reactive oxygen species can modify ion currents in cardiomyocytes (24-26). Therefore, we sought to determine whether the loss of Dct promotes atrial arrhythmias, at least in part, by affecting reactive oxygen species.
We performed invasive electrophysiology studies in $D c t^{--}$mice treated with the oxidant scavenger tempol for 1 week and compared them with $D c t^{-1}$ mice treated with vehicle. $D c t^{/} /$mice treated with tempol had approximately $68 \%$ fewer atrial arrhythmia episodes compared with vehicle-treated controls (tempol: 7 episodes in 3 of 10 mice lasting $957 \pm 671 \mathrm{~ms}$; vehicle: 22 episodes in 7 of 10 mice lasting $877 \pm 325 \mathrm{~ms}$; Table 6). There were no significant changes in conduction intervals or refractory periods induced by tempol (Table 6). These findings suggest that reactive oxygen species contribute to atrial arrhythmia triggers in the absence of Dct.

Dct ${ }^{\top-}$ cardiac melanocyte-like cells display prolonged repolarization and triggered activity. The lack of structural abnormalities or alterations in atrial refractoriness suggests that loss of Dct induces arrhythmogenesis by promoting triggered activity. Dermal melanocytes express voltage-dependent ion channels (22); therefore, we hypothesized that Dct-positive cells in the heart are excitable and can act as arrhythmogenic triggers. To test this hypothesis, we performed whole-cell current clamp recordings (51) from primary cultures. These studies revealed action potential prolongation in $D c t^{-/}$cardiac melanocytes (Figure 9, A and B, and Table 7), while $D c t^{+/}$cells and atrial myocytes of either genotype had comparable action potential duration (Table 7). Such profound prolonged repolarization likely promotes elevations in diastolic calcium (52) and afterdepolarizations. Consistent with these findings, we observed afterdepolarizations arising from phase 3 of spontaneous action potentials in $\mathrm{Dct}^{-/}$ cardiac melanocytes, while afterdepolarizations were not observed in $\mathrm{Dct}^{+/}$- cells (Figure 9C). In addition, fluorescent calcium imaging revealed that $D c^{-/}$cardiac melanocytes generate frequent calcium oscillations, while $D c t^{+/}$cells demonstrate no such activity $(0 / 8$ control, 5/8 Dct ${ }^{\prime-} ; P=0.026$, Fisher's exact test; Figure 10). Finally, to determine whether Dct-expressing cells in the heart form electrical connections with neighboring cardiomyocytes, we performed Lucifer yellow dye transfer experiments. These studies clearly demonstrated functional gap junctions between Dct-expressing cells and neighboring cardiomyocytes (Figure 11, A-C). Supporting these findings, the gap junction protein Gjc1 (connexin 45) mRNA was significantly increased in our single-cell mRNA expression profiling of cardiac melanocytes, and we confirmed connexin 45 expression (53) in Dct-expressing cells by immunohistochemistry (Table 2, Supplemental Table 2, and Figure 11, D-F). These data suggest that downregulation of Dct promotes cellular excitability in murine cardiac melanocytes. Furthermore, we have evidence to support the ability of Dct-expressing cells to form functional gap junctions.

\section{Discussion}

We describe a population of melanocyte-like cells in the heart and PVs of mice and humans that appear to contribute to atrial arrhyth- 

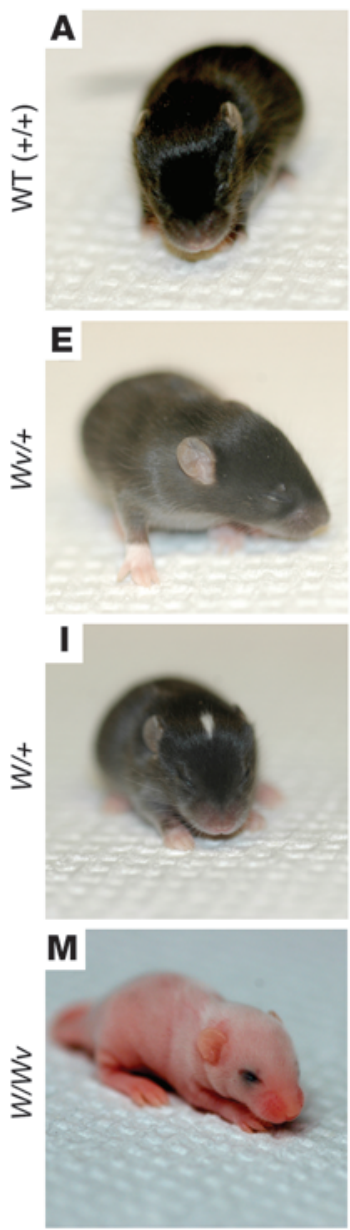
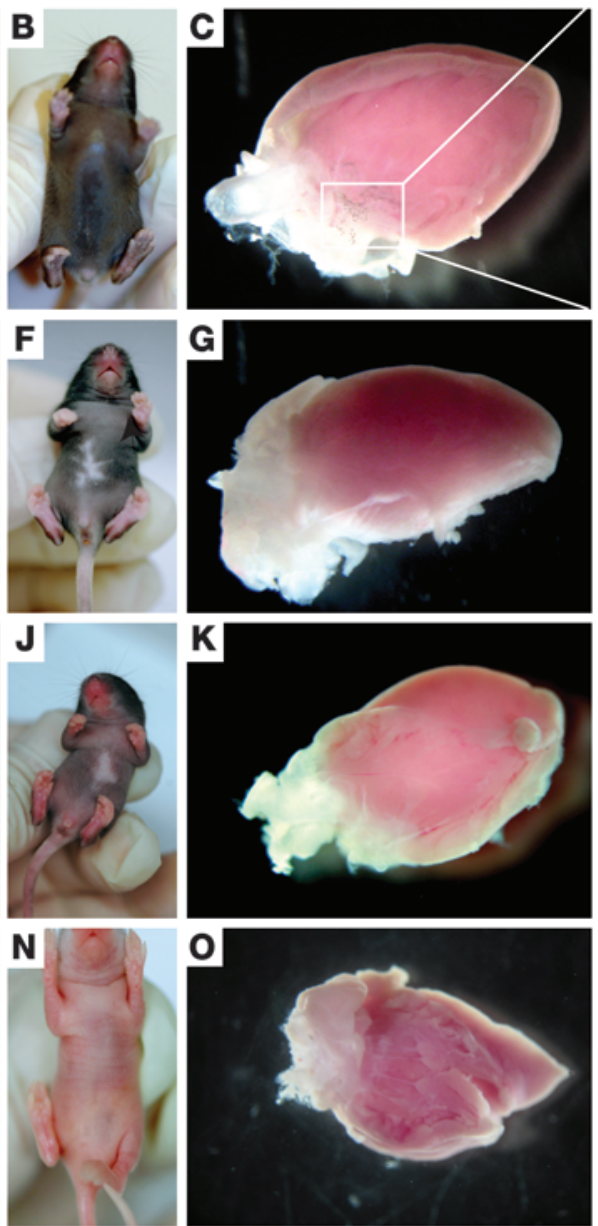
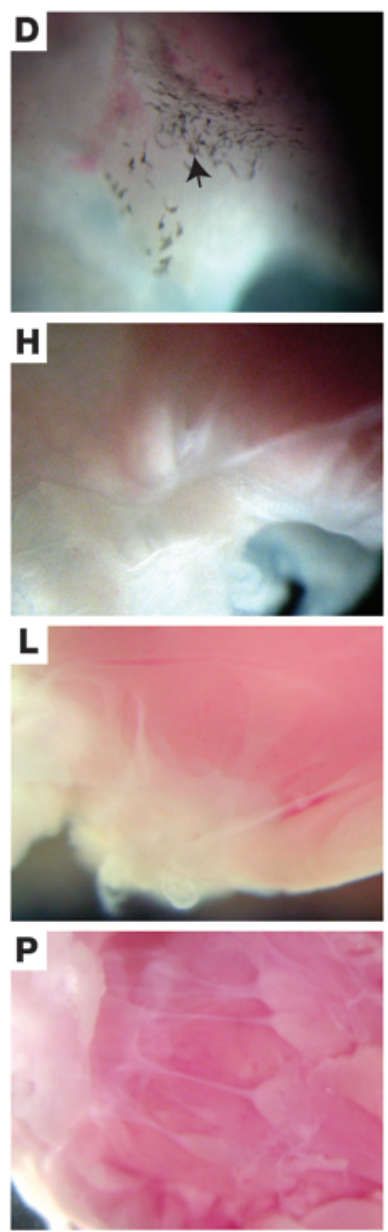

Figure 7

Dermal and cardiac pigmentation in W/Wv mice. Shown are representative hearts from wild-type (A-D), Wv/+ (E-H), W/+ (I-L), and W/Wv (M-P) littermates. The wild-type mouse demonstrated normal dermal pigmentation (A and $\mathbf{B})$ and the presence of cardiac pigmentation (C and $\mathbf{D})$. Tricuspid valve at low (C) and high power (D); black arrow denotes pigmented cells in a valve leaflet. $W V /+, W /+$, and $W / W v$ mice showed abnormal dermal pigmentation (E, F, I, J, M, and $\mathbf{N})$ as well as absence of pigmented cells within the valves $(\mathbf{G}, \mathbf{H}, \mathbf{K}, \mathbf{L}, \mathbf{O}$, and $\mathbf{P})$. Immunohistochemical staining with an anti-Dct antibody similarly showed labeling within wild-type mouse hearts, but cardiac staining was absent in $W v /+, W /+$, and W/Wv mice (not shown). Original magnification, $\times 40$ (C, G, K, and O); $\times 200(\mathbf{D}, \mathbf{H}, \mathbf{L}$, and P).

mogenesis. These cells display several features that implicate them as arrhythmogenic triggers. First, Dct-expressing cells reside within anatomic regions known for triggering clinical atrial arrhythmias. Second, they display cardiomyocyte-like excitability and calcium handling characteristics. Third, these cells express adrenergic and muscarinic receptors, appear to interact with autonomic nerves, and can be influenced by autonomic effluxes. Finally, atrial arrhythmias cannot be elicited in mice that lack Dct-expressing cells.

In the murine heart, Dct-positive cells express adrenergic and muscarinic receptors, and we have documented sympathetic and parasympathetic nerves that likely innervate these cells. In patients with clinical AF, a rise in sympathetic output precedes the onset of AF by $10-15$ minutes, followed by a dramatic rise in vagal output just prior to the onset of arrhythmia (46-48). Since Dct activity is increased by protein kinase A phosphorylation in dermal melanocytes (54), it is possible that Dct activity in cardiac melanocytes is downregulated by vagal output just before the onset of clinical AF. Downregulation of Dct activity in cardiac melanocyte-like cells may then result in higher oxidative stress that could modulate ion channels and calcium-handling proteins, thereby increasing cell excitability. Such increased excitability may then result in ectopy from cardiac melanocytes and trigger atrial arrhythmogenesis.

Along these lines, most cases of paroxysmal AF appear to be initiated by ectopy arising from the PVs, and Dct-positive cells are consistently expressed within murine and human PVs. In addition to their location around the PVs, we see a significant number of Dct-positive cells within the atrium, coronary sinus, and atrioventricular annulus. In the time since Haissaguerre et al. identified PV ectopy as triggers of AF (7), other studies have implicated atrial sites outside the PVs as a source of AF triggers (17) or ectopic atrial arrhythmias $(55,56)$. Sites that commonly contribute to atrial arrhythmogenesis correspond to the regions where we observe Dct-positive cells: the PVs, the posterior atrial wall, the atrioventricular annulus, and the coronary sinus. Therefore, the correlation between anatomical sites associated with clinical atrial arrhythmia initiation and the location of Dct-expressing cells is consistent with the suggestion that these cells may act as a source of arrhythmogenic triggers. 

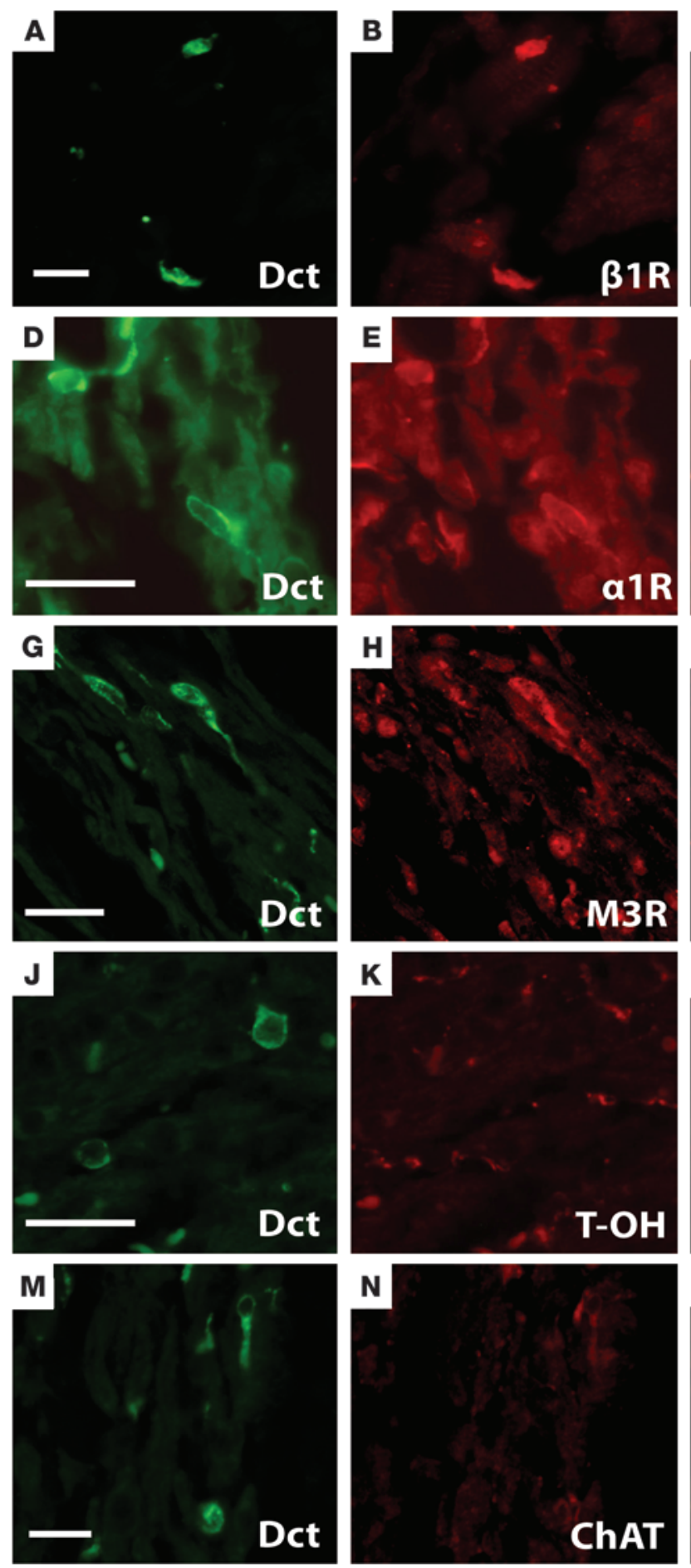
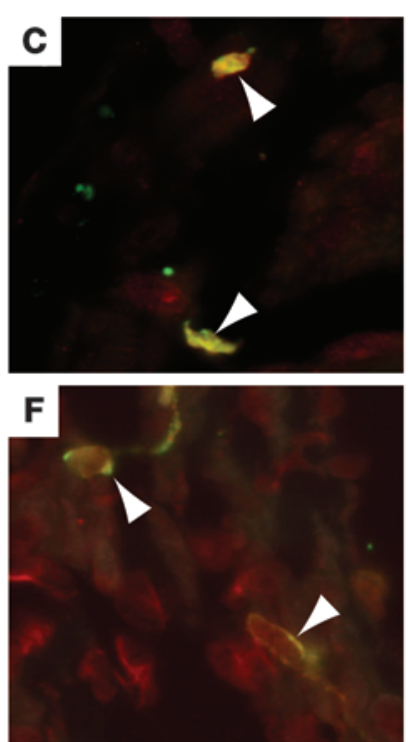

I
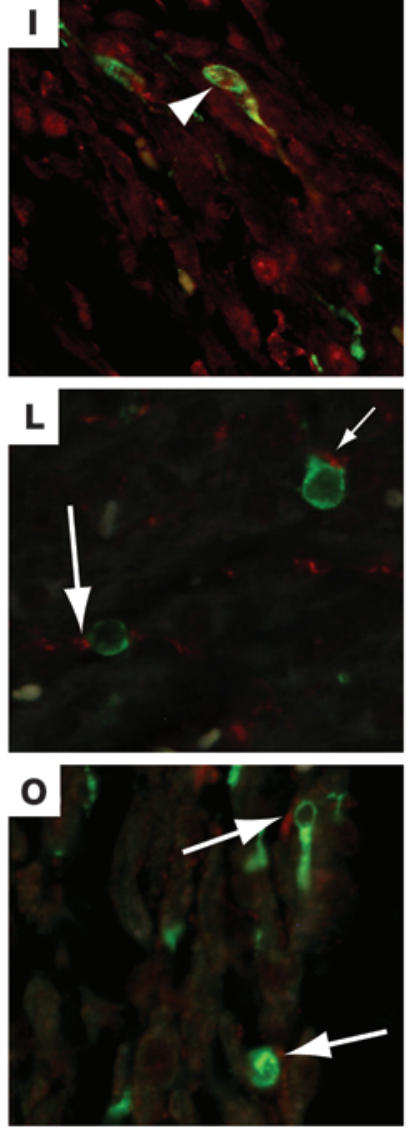

\section{Figure 8}

Dct-expressing cells coexpress adrenergic and muscarinic receptors. Immunohistochemistry within the adult mouse atrium using an antibody to Dct demonstrated Dct-positive cells with characteristic morphology (A, D, G, J, and $\mathbf{M}$ ). Sections were co-stained with antibodies to $\beta 1$-adrenergic receptor $(\beta 1 \mathrm{R} ; \mathbf{B}), \alpha 1$ adrenergic receptor ( $\alpha 1 \mathrm{R} ; \mathrm{E})$, muscarinic receptor subtype 3 (M3R; H), tyrosine hydroxylase ( $\mathrm{T}-\mathrm{OH} ; \mathbf{K})$, and choline acetyltransferase (ChAT; N). Merged images of Dct and each respective antibody are shown, demonstrating coexpression of Dct with $\beta 1 R(\mathbf{C}), \alpha 1 R(\mathbf{F})$, and M3R (I) receptors (arrowheads). Additionally, presumptive nerve terminals that express tyrosine hydroxylase (L) and choline acetyltransferase $(\mathbf{O})$ were seen in close proximity to Dct-expressing cells (arrows). Scale bars: $20 \mu \mathrm{m}$.
It is intriguing to speculate why Dct-expressing cells exist in the heart. In skin, the synthesis of melanin evolved to protect against damage from ionizing sunlight. In this setting, the enzymatic intermediaries of melanin synthesis are known to modulate calcium and reactive species (32). Consistent with this observation, cells with melanin synthesis enzymes in the PVs and heart may also exist to buffer calcium and reactive species. However, during pathologic processes, free radical and calcium-binding affinity may be altered or overwhelmed in these cells, transforming them into initiators of triggered activity and cardiac arrhythmias. The fact that tempol reduces atrial arrhythmia inducibility in $\mathrm{Dct}^{-1}$ mice suggests that reactive oxygen species contribute to cardiac melanocyte excitability and implies that these cells may also be involved with maintaining the normal balance of oxidative species in the myocardium.

In conclusion, Dct-expressing cells within the PVs and atrium appear to contribute to atrial arrhythmias. This interpretation is supported by the presence of induced and spontaneous arrhythmia 
Table 4

Electrophysiology effects of muscarinic stimulation with cardiac melanocytes

\begin{tabular}{|c|c|c|}
\hline \multirow[t]{2}{*}{ Parameter } & \multicolumn{2}{|c|}{ Wild-type mice $(n=8)$} \\
\hline & Baseline & Carbachol \\
\hline $\mathrm{AH}(\mathrm{ms})$ & $32.6 \pm 4.1^{A, B}$ & $43.0 \pm 5.2^{C, D}$ \\
\hline $\mathrm{H}_{\mathrm{d}}(\mathrm{ms})$ & $3.9 \pm 1.2$ & $4.1 \pm 1.0$ \\
\hline HV (ms) & $10.9 \pm 2.2$ & $11.2 \pm 2.4$ \\
\hline $\mathrm{AVI}(\mathrm{ms})$ & $47.7 \pm 5.8^{A, B}$ & $58.0 \pm 7.1^{C, D}$ \\
\hline $\mathrm{SNRT}_{120}(\mathrm{~ms})$ & $193.9 \pm 49.8^{A, B}$ & $340.4 \pm 67.2^{\mathrm{C}, \mathrm{D}}$ \\
\hline $\mathrm{SNRT}_{100}(\mathrm{~ms})$ & $206.7 \pm 55.0^{A, B}$ & $361.4 \pm 76.7^{\mathrm{C}, \mathrm{D}}$ \\
\hline AVWCL (ms) & $97.2 \pm 7.2^{\mathrm{A}, \mathrm{B}}$ & $107.8 \pm 6.6^{\mathrm{C}, \mathrm{D}}$ \\
\hline $\operatorname{AVERP}_{120}(\mathrm{~ms})$ & $70.5 \pm 7.9^{\mathrm{A}, \mathrm{B}}$ & $83.7 \pm 7.9 \mathrm{C}, \mathrm{D}$ \\
\hline $\operatorname{AERP}_{120}(\mathrm{~ms})$ & $38.6 \pm 6.8^{A, B}$ & $24.6 \pm 7.0 \mathrm{C}, \mathrm{D}$ \\
\hline $\mathrm{AERP}_{100}(\mathrm{~ms})$ & $39.6 \pm 6.4^{A, B}$ & $25.0 \pm 8.1 \mathrm{C}, \mathrm{D}$ \\
\hline Episodes of AT & $2^{A, B}$ & $64^{\mathrm{B}, \mathrm{C}, \mathrm{D}}$ \\
\hline ATCL (ms) & 36.4 & $26.7 \pm 8.7$ \\
\hline AT duration (s) & $0.19 \mathrm{~A}, \mathrm{~B}$ & $29.7 \pm 3.5^{C, D}$ \\
\hline Age (d) & $54.9 \pm 5.2$ & $54.9 \pm 5.2$ \\
\hline Weight (g) & $22.8 \pm 2.9$ & $22.8 \pm 2.9$ \\
\hline
\end{tabular}

\begin{tabular}{cc}
\multicolumn{2}{c}{ W/Wv mice $(\boldsymbol{n}=\mathbf{8})$} \\
Baseline & Carbachol \\
$31.7 \pm 4.5^{\mathrm{A}, \mathrm{B}}$ & $42.1 \pm 4.4^{\mathrm{C}, \mathrm{D}}$ \\
$4.0 \pm 1.2$ & $3.8 \pm 1.3$ \\
$11.0 \pm 2.1$ & $11.4 \pm 2.7$ \\
$46.5 \pm 5.2^{\mathrm{A}, \mathrm{B}}$ & $57.3 \pm 6.3^{\mathrm{C}, \mathrm{D}}$ \\
$225.1 \pm 69.8^{\mathrm{A}, \mathrm{B}}$ & $364.7 \pm 67.6^{\mathrm{C}, \mathrm{D}}$ \\
$209.2 \pm 58.9^{\mathrm{A}, \mathrm{B}}$ & $382.9 \pm 66.1^{\mathrm{C}, \mathrm{D}}$ \\
$99.4 \pm 7.4^{\mathrm{A}, \mathrm{B}}$ & $114.1 \pm 7.5^{\mathrm{C}, \mathrm{D}}$ \\
$72.4 \pm 6.9^{\mathrm{A}, \mathrm{B}}$ & $85.9 \pm 7.0^{\mathrm{C}, \mathrm{D}}$ \\
$39.7 \pm 5.6^{\mathrm{A}, \mathrm{B}}$ & $26.2 \pm 7.5^{\mathrm{C}, \mathrm{D}}$ \\
$40.8 \pm 5.2^{\mathrm{A}, \mathrm{B}}$ & $27.4 \pm 7.8^{\mathrm{C}, \mathrm{D}}$ \\
4 & $36^{\mathrm{A}, \mathrm{C}, \mathrm{D}}$ \\
$35.5 \pm 6.2$ & $25.0 \pm 8.2$ \\
$0.23 \pm 0.15^{\mathrm{A}, \mathrm{B}}$ & $27.8 \pm 2.9^{\mathrm{C}, \mathrm{D}}$ \\
$56.2 \pm 5.4$ & $56.2 \pm 5.4$ \\
$21.6 \pm 2.7$ & $21.6 \pm 2.7$
\end{tabular}

AP $<0.05$ compared with wild-type carbachol; ${ }^{B} P<0.05$ compared with $W / W v$ carbachol; ${ }^{C} P<0.05$ compared with wild-type; ${ }^{D} P<0.05$ compared with $W / W v$. Data analysis was performed as described in Table 3. in mice containing cardiac melanocytes that lack functional Dct, as well as by the absence of arrhythmia in mouse models that lack cardiac melanocytes (Kit mutants). Characteristics of these cells further add support to their role in arrhythmogenesis: since they reside in locations that clinically originate abnormal electrical activity, they are excitable and electrically coupled to neighboring myocytes, and this activity can be regulated through changes in autonomic tone. While there are currently no data that directly correlate Dct-positive cells or Dct activity to clinical atrial arrhythmias, the studies presented here suggest that further investigations into the role of Dct and cardiac melanocytes in clinical atrial arrhythmias are warranted. Such studies may not only enhance our mechanistic understanding of some forms of atrial arrhythmias, but may also lead to effective therapies for $\mathrm{AF}$ by selectively targeting these cells.

\section{Methods}

Animals. The creation of Dct-Cre (43), Dct-LacZ transgenic (57), Wnt1Cre transgenic (36), and Pax3Cre knockin mice (40) has been previously described. R26R Gt(ROSA)26Sor (41) and the Z/EG transgenic

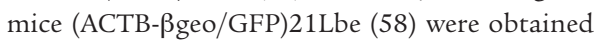
from The Jackson Laboratory. All mice used in this study were inbred 5 generations or more on a C57BL/6 background. Wnt1Cre, Pax3Cre knockin, and Dct-Cre knockin mice were each crossed with R26R $\beta$-galactosidase reporter mice. All protocols conformed to the guidelines established by the Association for the Assessment and Accreditation of Laboratory Animal Care and were approved by the University of Pennsylvania Animal Care and Use Committees.

$\beta$-Galactosidase activity staining. Whole-mount and tissue specimens were stained for $\beta$-galactosidase activity using previously described protocols (59,
60). Briefly, hearts from fetal mice E10.5 and older were dissected from embryos, placed in PBS, rinsed of blood, fixed in 2\% PFA for 30 minutes, and incubated in X-gal solution at $55^{\circ} \mathrm{C}$ overnight. Wild-type littermate controls, without the Dct-LacZ transgene, were processed side by side in the same manner.

In situ hybridization. In situ hybridization was performed as previously described (61) using a Dct antisense probe corresponding to GenBank NM_010024 as described in refs. 45, 60, 61.

Immunohistochemistry. Immunohistochemistry was performed on paraffin-embedded tissue fixed in $2 \%$ paraformaldehyde. Explanted human PVs were provided for these studies by J. Cooper and P. Sanchez (University of Pennsylvania). Antigen was exposed using Bull's Eye reagent (Biocare Medical) and heated in a pressure cooker. Antibodies utilized were mouse monoclonal anti-Pax3 (1:800; Developmental Studies Hybridoma Bank), monoclonal mouse anti- $\alpha$-actin (1:20; Dako), rabbit polyclonal anti- $\beta$-galactosidase (1:200; Cortex), rabbit anti-tyrosine hydroxylase (1:100; Chemicon), mouse monoclonal anti-neurofilament $(2 \mathrm{H} 3)$ (1:25; Developmental Studies Hybridoma Bank), mouse monoclonal anti-Mitf (1:5; Novocastra), rabbit polyclonal anti-Sox10 (1:200; Chemicon), goat polyclonal anti-Dct (1:100), goat anti-Tyrp1 (1:100), goat anti-Tyr (1:100; Santa Cruz Biotechnology Inc.), rabbit anti-connexin 40 (1:20; Zymed), rabbit anti-connexin 45 (1:100; provided by R. Gourdie, Medical University of South Carolina, Charleston, South Carolina, USA), mouse monoclonal anti-Isl1 (1:50; Developmental Studies Hybridoma Bank), rabbit anti-fibronectin (1:100; Novus), rabbit anti- $\beta 1$-adrenergic receptor (1:100; Sigma-Aldrich), rabbit anti-M3-mucarinic receptor (1:50; Santa Cruz Biotechnology Inc.), rabbit anti- $\alpha 1$-adrenergic receptor (1:100; Sigma-Aldrich), and rabbit anti-choline acetyltransferase (1:100; Millipore). Secondary antibodies

\section{Table 5}

Electrophysiology effects of $\beta$-adrenergic inhibition with cardiac melanocytes

\begin{tabular}{|c|c|c|c|c|}
\hline \multirow[t]{2}{*}{ Parameter } & \multicolumn{2}{|c|}{ Wild-type mice $(n=8)$} & \multicolumn{2}{|c|}{$W / W v$ mice $(n=8)$} \\
\hline & Carbachol & $\begin{array}{l}\text { Propranolol } \\
\text { + carbachol }\end{array}$ & Carbachol & $\begin{array}{l}\text { Propranolol } \\
\text { + carbachol }\end{array}$ \\
\hline $\mathrm{AH}(\mathrm{ms})$ & $43.0 \pm 5.2$ & $46.8 \pm 6.4$ & $42.1 \pm 4.4$ & $45.3 \pm 5.8$ \\
\hline $\mathrm{H}_{\mathrm{d}}(\mathrm{ms})$ & $4.1 \pm 1.0$ & $4.3 \pm 1.1$ & $3.8 \pm 1.3$ & $4.2 \pm 1.0$ \\
\hline $\mathrm{HV}(\mathrm{ms})$ & $11.2 \pm 2.4$ & $11.1 \pm 2.7$ & $11.4 \pm 2.7$ & $11.0 \pm 2.1$ \\
\hline $\mathrm{AVI}(\mathrm{ms})$ & $58.0 \pm 7.1$ & $60.1 \pm 6.8$ & $57.3 \pm 6.3$ & $60.3 \pm 6.7$ \\
\hline $\mathrm{SNRT}_{120}(\mathrm{~ms})$ & $340.4 \pm 67.2$ & $363.8 \pm 74.2$ & $364.6 \pm 67.6$ & $379.2 \pm 75.7$ \\
\hline $\mathrm{SNRT}_{100}(\mathrm{~ms})$ & $360.9 \pm 76.7$ & $395.7 \pm 68.2$ & $383.2 \pm 66.1$ & $409.0 \pm 72.0$ \\
\hline AVWCL (ms) & $108.1 \pm 6.6^{\mathrm{A}, \mathrm{B}}$ & $126.8 \pm 7.6^{\mathrm{C}, \mathrm{D}}$ & $114.3 \pm 7.5^{\mathrm{A}, \mathrm{B}}$ & $129.2 \pm 8.2^{C, D}$ \\
\hline $\operatorname{AVERP}_{120}(\mathrm{~ms})$ & $83.7 \pm 7.9$ & $92.5 \pm 9.9$ & $85.9 \pm 7.0$ & $95.4 \pm 8.8$ \\
\hline $\mathrm{AERP}_{120}(\mathrm{~ms})$ & $24.6 \pm 7.0^{\mathrm{A}, \mathrm{B}}$ & $35.3 \pm 5.3^{C, D}$ & $26.2 \pm 7.5^{\mathrm{A}, \mathrm{B}}$ & $36.7 \pm 4.0^{C, D}$ \\
\hline $\mathrm{AERP}_{100}(\mathrm{~ms})$ & $25.0 \pm 8.1^{A, B}$ & $36.0 \pm 5.6^{C, D}$ & $27.1 \pm 7.8^{\mathrm{A}, \mathrm{B}}$ & $34.9 \pm 4.6^{C, D}$ \\
\hline Episodes of AT & $64 A, B, D$ & $38^{B, C, D}$ & $36^{A, B, C}$ & $30^{A, C, D}$ \\
\hline ATCL (ms) & $27.7 \pm 8.7$ & $35.6 \pm 7.5$ & $29.0 \pm 8.2$ & $38.4 \pm 7.9$ \\
\hline AT duration (s) & $29.7 \pm 3.5^{\mathrm{A}, \mathrm{B}}$ & $24.1 \pm 3.2^{C, D}$ & $27.8 \pm 2.9^{A, B}$ & $23.6 \pm 2.6^{C, D}$ \\
\hline Age (d) & $54.9 \pm 5.2$ & $54.9 \pm 5.2$ & $56.2 \pm 5.4$ & $56.2 \pm 5.4$ \\
\hline Weight (g) & $22.8 \pm 2.9$ & $22.8 \pm 2.9$ & $21.6 \pm 2.7$ & $21.6 \pm 2.7$ \\
\hline
\end{tabular}

AP $<0.05$ compared with wild-type propranolol plus carbachol; ${ }^{\mathrm{B} P}<0.05$ compared with $W / W v$ propranolol plus carbachol; ${ }^{C} P<0.05$ compared with wild-type carbachol; ${ }^{D} P<0.05$ compared with $W / W v$ carbachol. Data analysis was performed as described in Table 3. 


\section{Table 6}

Electrophysiological effects of tempol in Dct- mice

\begin{tabular}{|c|c|c|}
\hline Parameter & Vehicle $(n=10)$ & Tempol $(n=10)$ \\
\hline $\mathrm{AH}(\mathrm{ms})$ & $32.5 \pm 5.3$ & $33.1 \pm 6.0$ \\
\hline $\mathrm{H}_{\mathrm{d}}(\mathrm{ms})$ & $4.4 \pm 1.4$ & $4.1 \pm 1.1$ \\
\hline $\mathrm{HV}$ (ms) & $11.5 \pm 2.6$ & $11.2 \pm 1.8$ \\
\hline $\mathrm{AVI}(\mathrm{ms})$ & $49.0 \pm 6.5$ & $49.1 \pm 6.8$ \\
\hline $\operatorname{SNRT}_{120}(\mathrm{~ms})$ & $215 \pm 54.8$ & $227 \pm 52.7$ \\
\hline $\mathrm{SNRT}_{100}(\mathrm{~ms})$ & $187 \pm 78.3$ & $212 \pm 66.4$ \\
\hline AVWCL (ms) & $96.7 \pm 7.0$ & $98.9 \pm 7.6$ \\
\hline $\operatorname{AVERP}_{120}(\mathrm{~ms})$ & $72.8 \pm 9.2$ & $76.2 \pm 10.4$ \\
\hline $\mathrm{AERP}_{120}(\mathrm{~ms})$ & $40.8 \pm 6.3$ & $43.6 \pm 5.8$ \\
\hline $\mathrm{AERP}_{100}(\mathrm{~ms})$ & $39.6 \pm 4.8$ & $42.0 \pm 5.2$ \\
\hline $\operatorname{VERP}_{120}(\mathrm{~ms})$ & $35.0 \pm 10.7$ & $36.4 \pm 10.1$ \\
\hline $\operatorname{VERP}_{100}(\mathrm{~ms})$ & $36.2 \pm 8.7$ & $34.7 \pm 9.4$ \\
\hline Episodes of AT & 22 & $7^{A}$ \\
\hline Episodes VT & 8 & 9 \\
\hline Mean ATCL (ms) & $28.9 \pm 12.8$ & $27.2 \pm 11.6$ \\
\hline Mean AT duration (ms) & $877 \pm 325$ & $957 \pm 671$ \\
\hline Age $(d)$ & $59.2 \pm 5.7$ & $60.5 \pm 5.2$ \\
\hline Weight (g) & $22.9 \pm 4.1$ & $21.6 \pm 3.8$ \\
\hline
\end{tabular}

conjugated with fluorescent tags (Alexa Fluor; Molecular Probes) were used at a dilution of 1:250.

Invasive electrophysiology. Protocols for in vivo mouse electrophysiology studies have been previously described in detail $(60,62)$. Briefly, adult mice (8-10 weeks old) and age- and sex-matched control littermates were anesthetized with pentobarbital ( $33 \mathrm{mg} / \mathrm{kg}$ i.p.). Surface ECGs were obtained using 26-gauge needles placed s.c. under each limb. A right jugular venous cut-down was performed, and a 1.7-Fr octapolar electrode catheter (CIBer mouse EP; NuMed) was positioned in the right atrium and ventricle under intracardiac electrogram guidance. Rectal temperature was monitored and maintained at $34^{\circ} \mathrm{C} \pm 1{ }^{\circ} \mathrm{C}$. Invasive studies were performed in 75 mice: $11 \mathrm{Dct}^{-/}$and $12 \mathrm{Dct}^{+/-} ; 8 \mathrm{~W} / \mathrm{Wv} ; 8 \mathrm{Dct} /-\mathrm{W} / \mathrm{Wv}$; and $10 \mathrm{Dct}^{-/-}$treated with tempol (Sigma-Aldrich; $29 \mathrm{mM}$ p.o. in drinking water with $4 \%$ sucrose for 1 week); $10 \mathrm{Dct}^{-/}$mice treated with drinking water plus $4 \%$ sucrose (vehicle); and $8 \mathrm{~W} / \mathrm{W} v$ and 8 wild-type mice treated with carbachol (Sigma-Aldrich; $20 \mu \mathrm{g} / \mathrm{kg}$ i.p.) and propranolol (Sigma-Aldrich; $20 \mathrm{mg} / \mathrm{kg}$ i.p.). Only atrial stimulation was performed during studies with carbachol and propranolol. Intracardiac electrograms were recorded and displayed simultaneously with surface ECG leads on a multichannel oscilloscope (Bard Electrophysiology) and stored on optical disks for off-line analysis. Programmed electrical stimulation was delivered using a digital stimulator (DTU-215A; Bloom Associates) following standard pacing protocols to assess atrial and ventricular conduction, refractoriness, and arrhythmia inducibility using up to 3 extrastimuli and burst pacing. Impulses were delivered at twice diastolic threshold with pulse duration of $1.0 \mathrm{~ms}$. We defined an atrial arrhythmia as 3 or more atrial beats with a cycle length of $90 \%$ or less than the preceding sinus cycle length with a different P-wave morphology than sinus rhythm. Surface ECG intervals were measured in 6-limb leads by 2 experienced, independent observers blinded to the animal's genotype.

Ambulatory ECG monitoring. Miniature telemetry transmitter devices (Data Science International) were implanted as previously described (63). Once the mice fully recovered from the implantation procedure (after
7 days), their cardiac ECGs were recorded during regular physical activity for 24 hours to detect any signs of spontaneous arrhythmia or AV conduction disturbances. Signals were stored on the hard drive of a Windowsbased PC for off-line analysis. We recorded electrograms from $4 \mathrm{Dct}^{-1-}$ mice as well as age- and sex-matched heterozygote littermates.

Ultrasound imaging and Doppler echocardiography. An Accuson ultrasound system with a $30-\mathrm{MHz}$ transducer was used to scan $D c t^{-/}$, Kit mutant, and control littermate mice anesthetized with isoflurane ( $3 \%$ induction followed by $1 \%-2 \%$ maintenance dose) on a heating pad as previously described (64). ECG electrodes and a rectal probe were used to monitor heart rate $(450-550 \mathrm{bpm})$ and body temperature $\left(36^{\circ} \mathrm{C}-37^{\circ} \mathrm{C}\right)$, respectively. Hair was removed from the abdomen, and prewarmed ultrasound gel was applied. Two-dimensional, M-mode, color flow, and spectral Doppler imaging was then performed. Atrial and ventricular fractional shortening was calculated offline using analytic software (VisualSonics). The percentage shortening fraction was calculated from M-mode measurements using the leading edge method via the formula: \%SF $=[\operatorname{LVID}(\mathrm{d})-\operatorname{LVID}(\mathrm{s})] / \operatorname{LVID}[\mathrm{d}])$, where $\% \mathrm{SF}$ is percentage shortening fraction, $\operatorname{LVID}(\mathrm{d})$ is left ventricular internal diameter (diastole), and LVID(s) is left ventricular internal diameter (systole).

Monolayer preparation. This protocol is a modification of the method described by Freshney (65). Briefly, P0.5 to P1 hearts from $D c t^{-/}$or $D c t^{+/-}$ mice with the Z/EG transgene were dissected from pups, washed in PBS, splayed open, and incubated overnight (6-18 hours) in calcium-free HBSS, $10 \mathrm{mM}$ HEPES, $0.5 \%$ trypsin, and $0.54 \mathrm{mM}$ EDTA at $4^{\circ} \mathrm{C}$. The trypsin solution was then aspirated, and individual hearts were incubated at $37^{\circ} \mathrm{C}$ for 30 minutes in 6-well dishes. Each heart was then transferred to a 15 -ml tube and triturated with a medium bore transfer pipette 10-30 times in $5 \mathrm{ml}$ calcium-free HBSS with $10 \%$ horse serum, $5 \%$ FBS, $10 \mathrm{mM}$ HEPES buffer, and $1 \%$ penicillin/streptomycin. Cells were centrifuged at $680 \mathrm{~g}$ at $4^{\circ} \mathrm{C}$. Pellets were then rinsed in $10 \mathrm{ml}$ of calcium-free DMEM with $10 \%$ horse serum, $5 \% \mathrm{FBS}$, and $1 \%$ penicillin/streptomycin and gently resuspended without aerating the solution. This solution was respun at $680 \mathrm{~g}$ at $4^{\circ} \mathrm{C}$. The pellet was then gently resuspended in $3 \mathrm{ml}$ Opti-MEM with $10 \%$ horse serum, $5 \%$ FBS, and $1 \%$ penicillin/streptomycin. The solution was transferred through a $70-\mu \mathrm{m}$ strainer onto $25-\mathrm{mm}$ glass coverslips pre-plated with laminin at $10 \mu \mathrm{g} / \mathrm{cm}^{2}$. Cells were then incubated at $37^{\circ} \mathrm{C}$ in $5 \% \mathrm{CO}_{2}$. After 48 hours, the solution was removed and replaced with Opti-MEM with $0.7 \%$ horse serum, $0.3 \%$ FBS, and $1 \%$ penicillin/streptomycin. Patch clamp and calcium imaging studies were performed on the second day after plating when monolayers beat spontaneously and reached $70 \%-80 \%$ confluence, since this was the time point at which GFP fluorescence appeared and cells were sufficiently dispersed to record from individually.

Cellular electrophysiology. Current clamp recordings were performed using the patch clamp technique in the whole-cell configuration described by Hamill et al. (51). Briefly, gigaohm seals were achieved using pipettes fashioned from borosilicate glass (Harvard Apparatus) with resistances of 2-2.5 $\mathrm{M} \Omega$ after fire polishing. Recordings were obtained from neonatal cardiomyocytes and Dct-expressing cells 2 days after dissociation. Action potentials were recorded from spontaneously contracting cells or elicited using an Axopatch 200B amplifier by injecting $0.2-0.5 \mathrm{nA}$ pulses at $1 \mathrm{~Hz}$ or $6 \mathrm{~Hz}$ with a 2-ms duration controlled by a Pentium 4-based computer running the pClamp program (version 9.2; Molecular Devices). Voltage recordings were filtered at $1-2 \mathrm{kHz}$ and digitized at $25 \mathrm{kHz}$ using the Digidata $1332 \mathrm{~A}$ $\mathrm{A} / \mathrm{D}$ converter (Molecular Devices). Only cells with resting potentials lower than $-50 \mathrm{mV}$, seal resistances $\geq 500 \mathrm{M} \Omega$, and access resistance less than 10 $\mathrm{M} \Omega$ were accepted for analysis. For current clamp recordings, pipette solution contained $110 \mathrm{mM} / 1 \mathrm{KCl}, 5 \mathrm{mM} / 1 \mathrm{Na}_{2}$-ATP, $11 \mathrm{mM} / 1$ EGTA, $10 \mathrm{mM} / 1$ HEPES, $1 \mathrm{mM} / \mathrm{l} \mathrm{CaCl}_{2}, 1 \mathrm{mM} / 1 \mathrm{MgCl}_{2}$, $\mathrm{pH} 7.3$, with $\mathrm{KOH}$, and bath solution contained $132 \mathrm{mM} / 1 \mathrm{NaCl}, 4.8 \mathrm{mM} / 1 \mathrm{KCl}, 10 \mathrm{mM} / 1$ HEPES, $2 \mathrm{mM} / \mathrm{l} \mathrm{CaCl}_{2}$, $1.2 \mathrm{mM} / 1 \mathrm{MgCl}_{2}, \mathrm{pH} 7.4$, with $\mathrm{NaOH}$. 
A

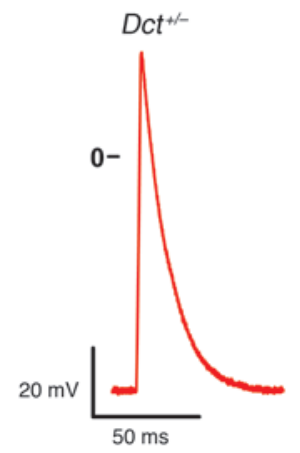

B

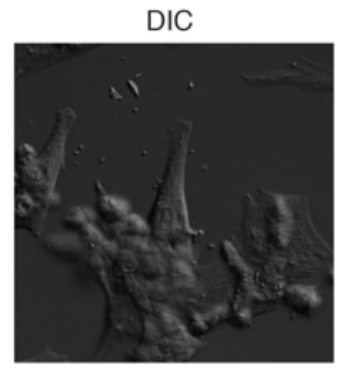

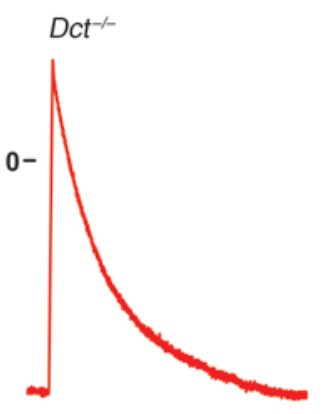

GFP

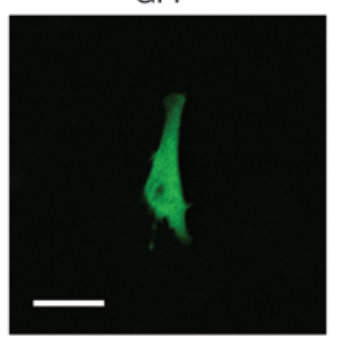

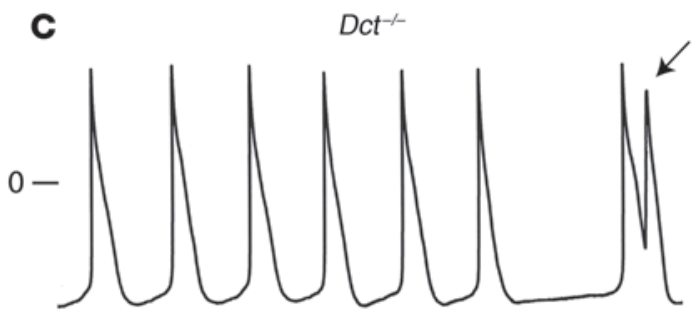

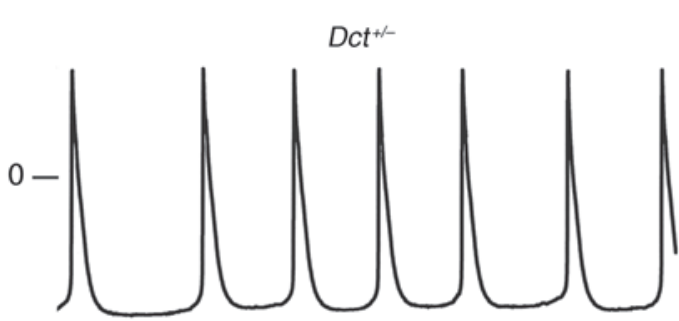

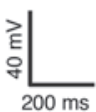

Figure 9

$D c t^{-1}$ cardiac melanocytes demonstrate prolonged action potential duration and afterdepolarizations. (A) Current clamp recordings from cardiac $\mathrm{Dct}^{+/-}$and $\mathrm{Dct}^{-1-}$ cells demonstrated increased action potential duration in the absence of Dct. Resting potential of the $D c t^{+/-}$cell was $-62 \mathrm{mV}$, while the $\mathrm{Dct}^{-/}$cell had a resting potential of $-60 \mathrm{mV}$. (B) Representative cardiac melanocyte from a $D c t^{+-}$, Z/EG mouse visualized by DIC and fluorescence (GFP). Scale bar: $10 \mu \mathrm{m}$. (C) Spontaneous action potential recordings from $\mathrm{Dct}^{-1-}$ and $D c t^{+/-}$cardiac melanocytes. Within the trace from the $D c t^{-1}$ cell, note the presence of an early afterdepolarization (arrow) arising from phase 3 of the preceding action potential. The trace from a $\mathrm{Cct}^{+/-}$cell is included for comparison.

Calcium imaging. Changes in intracellular calcium concentration $\left(\left[\mathrm{Ca}^{2}\right]_{\mathrm{i}}\right)$ were assessed using Fluo-4/AM (Invitrogen) as described previously (66). Prior to incubation with Fluo-4/AM, spontaneously beating cells adherent to 25 -mm glass coverslips were affixed to a chamber on the stage of an inverted microscope (model TE300; Nikon). Cells were excited with a $\mathrm{Kr} / \mathrm{Ar}$-ion laser at $488 \mathrm{~nm}$ to identify GFP-positive cells at an emission wavelength of $510 \mathrm{~nm}$. These cells were placed in the center of the visual field, and the dish was subsequently incubated at room temperature in $5 \mathrm{mM}$ Fluo-4/AM for 30 minutes, followed by 10 minutes in dye-free medium. Coverslips were maintained in a PDMI-2 open perfusion microincubator (Harvard Apparatus) at $37^{\circ} \mathrm{C}$. Confocal imaging was performed using the Radiance 2000 imaging system (Bio-Rad Laboratories) equipped with a $\mathrm{Kr} / \mathrm{Ar}$-ion laser source at $488 \mathrm{~nm}$ excitation using a $\times 60$ oil objective. Images were collected using LaserSharp software (Bio-Rad Laboratories) at $0.862 \mathrm{~ms} /$ line for $\left[\mathrm{Ca}^{2}\right]_{\mathrm{i}}$ changes. Cellular health was confirmed in parallel experiments through direct measurement of resting membrane potential (current clamp experiments). Furthermore, current traces were performed on GFP-positive cells with uptake and cleavage of Fluo-4/AM ester and contiguous with adjacent myocytes that beat spontaneously. Resultant line scans were analyzed using the Metamorph analysis software (version 7; Molecular Devices).

Electron microscopy. The electron microscopy method has been previously published $(67,68)$. Briefly, we performed electron microscopy on hearts that labeled Dct-expressing cells with the Dct-LacZ transgene (57). Hearts were harvested from P1 pups and fixed with $0.5 \%$ glutaraldehyde for 10 minutes. After initial fixation, the sections were washed with PBS 3 times and subsequently placed in X-gal solution for 4 hours. The results were monitored by microscopy. Hearts were then washed again with PBS 3 times for 5 minutes each, followed by fixation with $2.5 \%$ glutaraldehyde for 1 hour. The samples were placed in sodium cacodylate buffer and the X-gal-positive area dissected and postfixed with $1 \%$ osmium tetroxide for 1 hour. Tissues were further washed with sodium cacodylate buffer, followed by en bloc stain with $1 \%$ uranyl acetate for 1 hour in the dark. Tissues were then dehydrated with ethanol and infiltrated with epoxy resin, and these specimens were polymerized at $68^{\circ} \mathrm{C}$ for 48 hours. Semi-thin sections ( 1 micron) were cut to select the X-gal-posi-
Table 7

Action potential parameters

\begin{tabular}{lcccc} 
Parameter & \multicolumn{2}{c}{ Cardiac melanocytes } & \multicolumn{2}{c}{ Atrial myocytes } \\
& $\boldsymbol{D c t}^{+--}(\boldsymbol{n}=\mathbf{7})$ & $\boldsymbol{D c t}^{-/-}(\boldsymbol{n}=\mathbf{7})$ & $\boldsymbol{D c t}^{+-}(\boldsymbol{n}=\mathbf{8})$ & $\boldsymbol{D c t}^{--}(\boldsymbol{n}=\mathbf{8})$ \\
$\mathrm{APD}_{90}(\mathrm{~ms})$ & $17.0 \pm 3.8^{\mathrm{A}}$ & $75.5 \pm 22.2^{\mathrm{B}, \mathrm{C}, \mathrm{D}}$ & $15.2 \pm 1.0^{\mathrm{A}}$ & $14.6 \pm 1.72^{\mathrm{A}}$ \\
$\mathrm{APD}_{50}(\mathrm{~ms})$ & $9.2 \pm 4.0^{\mathrm{A}}$ & $19.3 \pm 8.0^{\mathrm{B}, \mathrm{C}, \mathrm{D}}$ & $5.7 \pm 1.0^{\mathrm{A}}$ & $5.2 \pm 1.5^{\mathrm{A}}$ \\
$\mathrm{dV} / \mathrm{dt}(\mathrm{mV} / \mathrm{ms})$ & $37.8 \pm 14.7$ & $35.7 \pm 12.0$ & $30.1 \pm 8.1$ & $34.0 \pm 8.7$ \\
$\mathrm{~V}_{\mathrm{r}}(\mathrm{mV})$ & $-59.3 \pm 8.9$ & $-65.7 \pm 12.9$ & $-61.1 \pm 9.2$ & $-62.3 \pm 12.8$
\end{tabular}

${ }^{A} P<0.05$ compared with $D c t^{-1}$ melanocytes; ${ }^{B} P<0.05$ compared with $D c t^{+/-}$melanocytes; ${ }^{c} P<0.05$ compared with $D c t^{+/-}$myocytes; ${ }^{D} P<0.05$ compared with $D c t^{-1}$ myocytes. APD 90, action potential duration at $90 \%$ repolarization; $\mathrm{dV} / \mathrm{dt}$, action potential upstroke rate of rise; $\mathrm{V}_{\mathrm{r}}$, resting membrane potential. Data are presented as the mean \pm SD, and statistical significance was assessed using 1-way ANOVA followed by Tukey post-hoc analysis. 
$D c t^{+/-}$

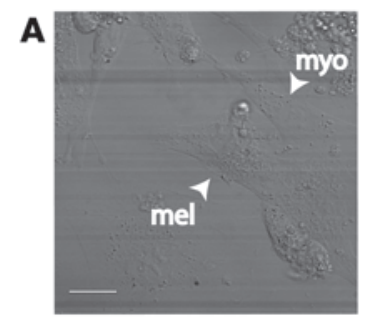

D

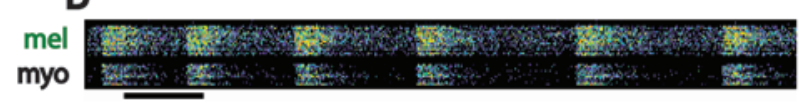

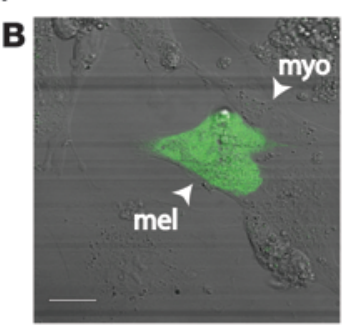

sesinic
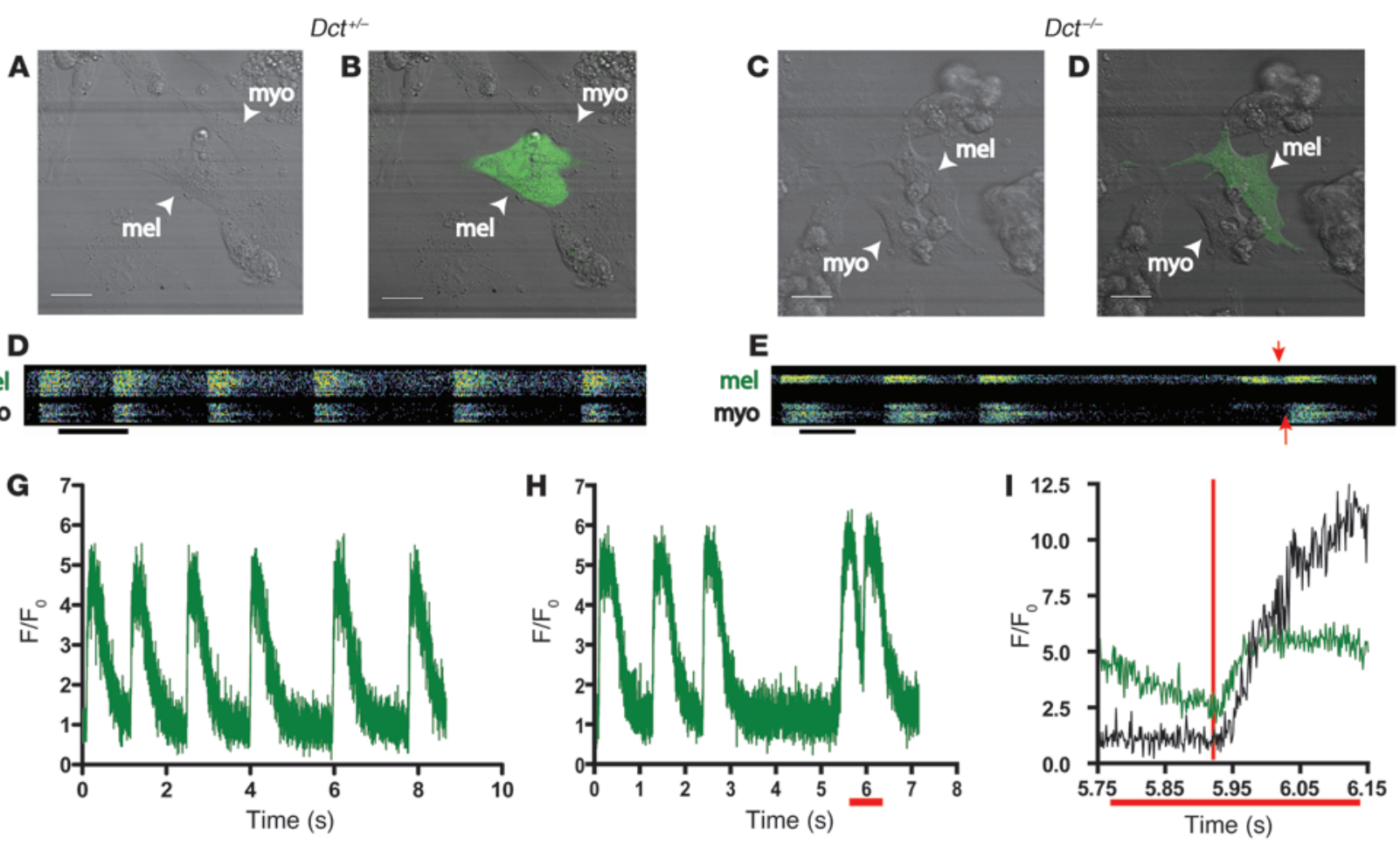
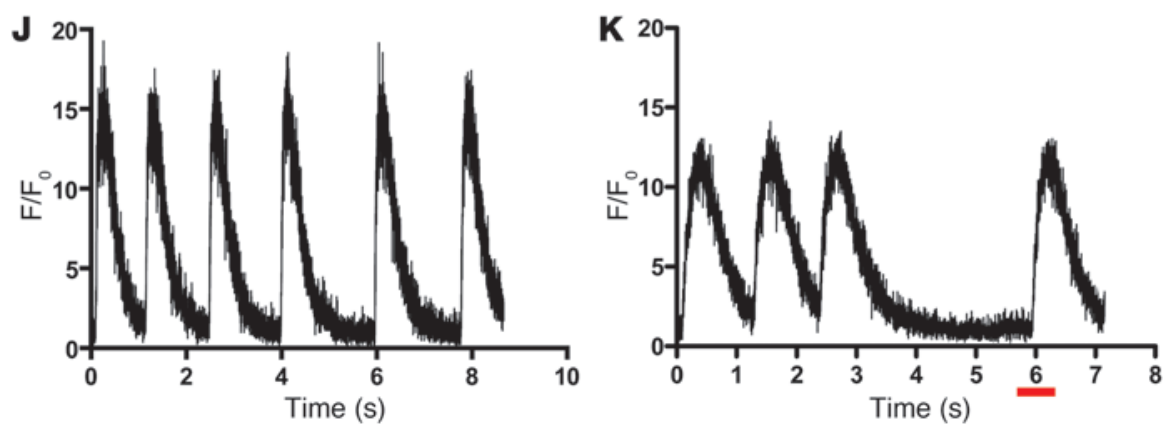

Figure 10

$D c t^{-1}$ cardiac melanocytes display spontaneous calcium oscillations. (A-D) Representative cells from $D c t^{+/-}$, Z/EG and $D c t^{/-}$, Z/EG hearts. A and C show DIC images; B and D show DIC images merged with fluorescent images demonstrating GFP-positive Dct-expressing cells. Mel, Dct-expressing cell; myo, atrial myocyte. Scale bars: $20 \mu \mathrm{m}$. (E and F) Representative linescans normalized to background from $\mathrm{Dct}^{+/-}(\mathbf{E})$ and $\operatorname{Dct}^{-1}(\mathbf{F})$ preparations demonstrated calcium mobilization in the Dct-expressing cell (mel) as well as an adjacent myocyte (myo). (G-K) Graphs demonstrating normalized calcium flux in a $\mathbf{D c t + / -}$ melanocyte $(\mathbf{G})$ and an adjacent myocyte $(\mathbf{J})$, as well as from a $D c t^{\prime-}$ melanocyte $(\mathbf{H})$ and an adjacent myocyte (K). Note an oscillation following the fourth complex in $\mathbf{H}$ characterized by a rapid upstroke prior to full repolarization of the preceding complex. (I) Portions of the graph in $\mathbf{H}$ and $\mathbf{K}$, denoted by the horizontal red bar, at a higher time resolution. Note that the upstroke of the oscillation in the melanocyte precedes calcium mobilization in the adjacent myocyte (vertical red bar). F/ $F_{0}$, measured fluorescence normalized to peak fluorescence.

tive areas for ultrathin sections. The sections, both unstained and stained with uranyl acetate/lead citrate, were analyzed using either a JEOL-1010 or FEI Tecnai T-12 electron microscope.

Single-cell RNA isolation and analysis. The method used is based upon previously described protocols with minor modifications (42). Briefly, primary culture of atrial myocytes, cardiac Dct-expressing cells, and dermal Dctexpressing cells were prepared as outlined above. At least 5 cells of each type were harvested from at least 2 different litters. All preparations were handled under identical conditions and solutions. Two days after plating, coverslips were placed on a warmed microscope stage and Dct-expressing cells were identified by fluorescence excitation at $488 \mathrm{~nm}$. Myocytes were identified by the absence of fluorescence and spontaneous contractions. A single cell was aspirated using a micropipette filled with 3\% RNasin
(Promega) in HBSS and placed in a microcentrifuge tube containing dNTPs (Amersham) 5X First Strand buffer (Invitrogen), dT-T7 oligo (Midland), and DTT (Invitrogen). The samples was incubated for 5 minutes at $70^{\circ} \mathrm{C}$ and then immediately placed on ice. The volume was brought up to $10.25 \mu \mathrm{l}$ with DEPC-treated water. A mixture containing RNasin and Superscript III (Invitrogen) was then added and the sample incubated for 2 hours at $50^{\circ} \mathrm{C}$. The resulting RNA/DNA hybrid was denatured for 15 minutes at $70^{\circ} \mathrm{C}$ and stored at $-20^{\circ} \mathrm{C}$. RNA concentration was determined by spectrophotometer. Samples were concentrated as need by vacuum centrifugation to obtain $6 \mu \mathrm{g}$ of RNA in $40 \mu$ l. RNA was hybridized to Affymetrix Mouse 4302.0 arrays without fragmentation and analyzed using GeneSpring software (version 7.3.1; Agilent Technologies). Raw data were normalized to the median per gene to the fiftieth percentile per sample. Any data point below 

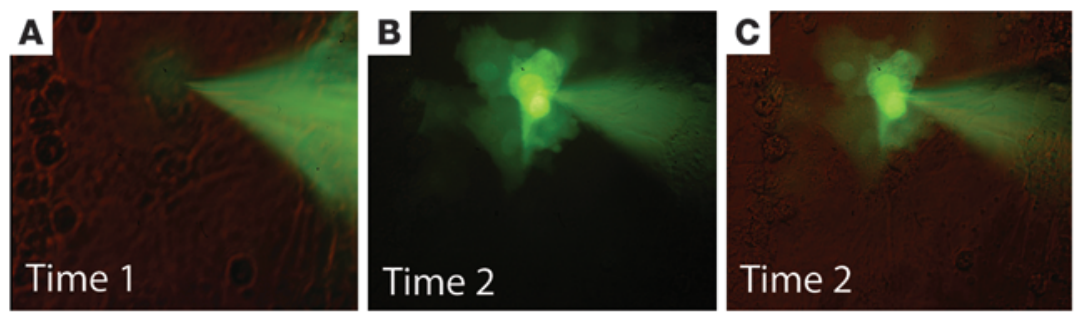

allowed to occur, and microphotographs were taken to verify dye transfer.

Statistics. All values are expressed as the mean \pm SD. Differences between 2 groups were analyzed using 2-tailed Student's $t$ test or, when not normally distributed, using a nonparametric Mann-Whitney $U$ test. Differences in means among multiple data sets were analyzed using 1- or 2-way ANOVA with treatment or genotype as the independent factors. When ANOVA showed significant
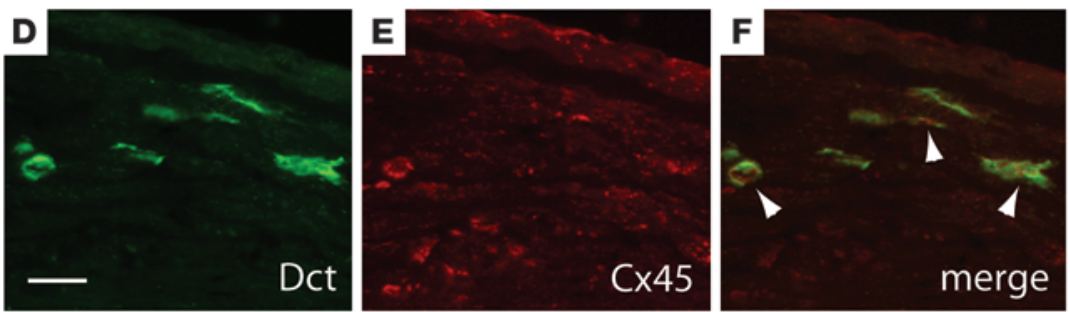
differences, pairwise comparisons between means were tested using Tukey post-hoc analysis. When data were not normally distributed, ANOVA on ranks was used with the Kruskal-Wallis test, followed by pairwise comparison using the Dunn test. The numbers of arrhythmic episodes were assumed to have a Poisson distribution, and the Kolmogorov-Smirnov test was used to assess statistical significance between groups. A $P$ value

\section{Figure 11}

Functional coupling of cardiac melanocytes with atrial myocytes and gap junction expression in cardiac melanocytes. (A-C) A lucifer dye transfer experiment demonstrated functional coupling between a Dct-expressing cell and an adjacent atrial myocyte in culture. (A) A patch pipette containing $250 \mu \mathrm{M}$ of lucifer yellow in the cell-attached configuration prior to membrane rupture (time 1). (B and C) Dct-expressing cardiac melanocyte in the whole-cell configuration after membrane rupture (time 2) visualized with fluorescence excited at $488 \mathrm{~nm}(B)$ and with both fluorescence and white light via Hoffman illumination (C). (D-F) Dct-positive cells in the atrium express connexin 45 (Cx45). Sections from an adult wild-type mouse atrium co-stained by immunofluorescence with Dct (D) and connexin $45(E)$. Dct-positive cells that coexpressed connexin 45 in the merge image (F) are indicated by arrowheads. Scale bar: $20 \mu \mathrm{m}$.

0.01 was set equal to 0.01 . ANOVA was then performed without assuming equal variance and a false discovery rate of 0.05 , and then filtered using a threshold of greater than 1 -fold change. Cluster analysis was also performed on normalized data using Pearson's correlation coefficient.

Quantitative RT-PCR. Protocols for quantitative RT-PCR have been described previously (64), using SYBR Green according to the manufacturer's protocol. Briefly, total RNA was isolated from single cardiac melanocytes and atrial myocytes as described above for single-cell RNA isolation, and $2 \mu \mathrm{g}$ of total RNA was reverse transcribed using an oligodT primer and the Super Script First-Strand Synthesis System (Invitrogen). PCR was performed with $5 \mu$ l of reverse-transcribed cDNA reaction mixture, $400 \mathrm{nmol} / \mathrm{l}$ of specific forward and reverse primers, and 1x SYBR Green PCR Master Mix (Applied Biosystems). Quantification of the reaction product was performed using the MJ Research DNA Engine Opticon 2 real-time detection system. The size of the amplicon for each PCR reaction (see Supplemental Table 3) was verified by gel electrophoresis. PCR cycle conditions were $95^{\circ} \mathrm{C}$ for 10 minutes, followed by 40 cycles of denaturation at $95^{\circ} \mathrm{C}$ for 15 seconds and annealing and extension at $60^{\circ} \mathrm{C}$ for 1 minute. Reactions were performed in triplicate with and without RT as controls. Cycle threshold values were converted to relative gene expression levels using the $2^{-\Delta \Delta \mathrm{Ct}}$ method. Primer pairs corresponding to each cDNA are listed in Supplemental Table 3.

Lucifer yellow dye transfer studies. Lucifer yellow dye transfer dye studies were performed as described previously (69). Briefly, monolayers were prepared as described above. High-resistance pipettes (12-14 M $\Omega$ ) were fashioned from borosilicate glass (Harvard Apparatus) and filled with $250 \mu \mathrm{m}$ lucifer yellow lithium salt (Invitrogen). Dct-expressing cells were identified by green fluorescence and photographed while the pipette in the cell attached patch configuration. The membrane was subsequently ruptured to create the whole-cell patch configuration, dye transfer was less than 0.05 was considered significant in all analyses (SigmaStat Statistical Software; Jandel Scientific).

\section{Acknowledgments}

We thank Joel Cooper and Pedro Sanchez for providing explanted human PV tissue, Robert Gourdie for the gift of the connexin 45 antibody, Michael Parmacek for reading and discussing the manuscript, Nicole Antonucci for technical help with breeding and maintaining the mouse colonies, Andrea Stout for help with microscopy, Ann Granger for helpful suggestions with the neonatal myocyte isolation protocol, and Rennie Grafstein for help with compiling figures. We also wish to thank Qian-Chun and Ray Meade for assistance with performing electron microscopy. This work was funded by grants from the NIH and the W.W. Smith Charitable Trust.

Received for publication March 5, 2009, and accepted in revised form August 25, 2009.

Address correspondence to: Vickas Patel, Penn Cardiovascular Institute, University of Pennsylvania, 905 BRB II/III, 421 Curie Blvd., Philadelphia, Pennsylvania 19104, USA. Phone: (215) 573-8990; Fax: (215) 572-2094; E-mail: patelv@mail.med.upenn.edu. Or to: Jonathan A. Epstein, Department of Cell and Developmental Biology, University of Pennsylvania, 1154 BRB II/III, 421 Curie Blvd., Philadelphia, Pennsylvania 19104, USA. Phone: (215) 898-8731; Fax: (215) 898-9871; E-mail: epsteinj@mail.med.upenn.edu.

Brian J. Hawkins's and Madesh Muniswamy's present address is: Department of Biochemistry, Temple University School of Medicine, Philadelphia, Pennsylvania, USA.

Deborah Lang's present address is: Section of Dermatology, Department of Medicine, University of Chicago, Chicago, Illinois, USA.

Jason T. Jacobson's present address is: Section of Cardiac Electrophysiology, Division of Cardiology, Northwestern Memorial Hospital, Chicago, Illinois, USA.

Christopher B. Brown's present address is: Department of Pediatrics, Vanderbilt University Medical Center, Nashville, Tennessee, USA. 
1. Carnes, C.A., et al. 2001. Ascorbate attenuates atrial pacing-induced peroxynitrite formation and electrical remodeling and decreases the incidence of postoperative atrial fibrillation. Circ. Res. 89:e32-e38.

2. Feinberg, W.M., Blackshear, J.L., Laupacis, A., Kronmal, R., and Hart, R.G. 1995. Prevalence, age distribution, and gender of patients with atrial fibrillation. Analysis and implications. Arch. Intern. Med. 155:469-473.

3. Wattigney, W.A., Mensah, G.A., and Croft, J.B. 2003. Increasing trends in hospitalization for atrial fibrillation in the United States, 1985 through 1999: implications for primary prevention. Circulation. 108:711-716.

4. Friberg, J., Buch, P., Scharling, H., Gadsbphioll, N., and Jensen, G.B. 2003. Rising rates of hospital admissions for atrial fibrillation. Epidemiology. 14:666-672.

5. Brand, F.N., Abbott, R.D., Kannel, W.B., and Wolf, P.A. 1985. Characteristics and prognosis of lone atrial fibrillation. 30-year follow-up in the Framingham Study. JAMA. 254:3449-3453.

6. Levy, S., et al. 1999. Characterization of different subsets of atrial fibrillation in general practice in France: the ALFA study. The College of French Cardiologists. Circulation. 99:3028-3035.

7. Haissaguerre, M., et al. 1998. Spontaneous initiation of atrial fibrillation by ectopic beats originating in the pulmonary veins. N. Engl. J. Med. 339:659-666.

8. Sauer, W.H., et al. 2006. Clinical predictors and outcomes associated with acute return of pulmonary vein conduction during pulmonary vein isolation for treatment of atrial fibrillation. Heart Rhythm. 3:1024-1028.

9. Dhruvakumar, S., and Gerstenfeld, E.P. 2007. Complications associated with catheter ablation of atrial fibrillation. Minerva Cardioangiol. 55:353-368.

10. Bernd, A., et al. 1994. Levels of dopachrome tautomerase in human melanocytes cultured in vitro. Melanoma Res. 4:287-291.

11. Bellandi, F., et al. 2001. Long-term efficacy and safety of propafenone and sotalol for the maintenance of sinus rhythm after conversion of recurrent symptomatic atrial fibrillation. Am. J. Cardiol. 88:640-645.

12. Kochiadakis, G.E., et al. 2000. Amiodarone, sotalol, or propafenone in atrial fibrillation: which is preferred to maintain normal sinus rhythm? Pacing Clin. Electrophysiol. 23:1883-1887.

13. Singh, B.N., et al. 2005. Amiodarone versus sotalol for atrial fibrillation. N. Engl. J. Med. 352:1861-1872.

14. Morel, E., Meyronet, D., Thivolet-Bejuy, F., and Chevalier, P. 2008. Identification and distribution of interstitial Cajal cells in human pulmonary veins. Heart Rhythm. 5:1063-1067.

15. Gherghiceanu, M., et al. 2008. Interstitial Cajal-like cells (ICLC) in myocardial sleeves of human pulmonary veins. J. Cell. Mol. Med. 12:1777-1781.

16. Cappato, R., et al. 2003. Prospective assessment of late conduction recurrence across radiofrequency lesions producing electrical disconnection at the pulmonary vein ostium in patients with atrial fibrillation. Circulation. 108:1599-1604.

17. Gerstenfeld, E.P., Callans, D.J., Dixit, S., Zado, E., and Marchlinski, F.E. 2003. Incidence and location of focal atrial fibrillation triggers in patients undergoing repeat pulmonary vein isolation: Implications for ablation strategies. J. Cardiovasc. Electrophysiol. 14:685-690.

18. Yajima, I., and Larue, L. 2008. The location of heart melanocytes is specified and the level of pigmentation in the heart may correlate with coat color. Pigment Cell Melanoma Res. 21:471-476.

19. Mjaatvedt, C.H., Kern, C.B., Norris, R.A., Fairey, S., and Cave, C.L. 2005. Normal distribution of melanocytes in the mouse heart. Anat. Rec. A Discov. Mol. Cell Evol. Biol. 285:748-757.
20. Brito, F.C., and Kos, L. 2008. Timeline and distribution of melanocyte precursors in the mouse heart. Pigment Cell Melanoma Res. 21:464-470.

21. Nakamura, T., Colbert, M.C., and Robbins, J. 2006. Neural crest cells retain multipotential characteristics in the developing valves and label the cardiac conduction system. Circ. Res. 98:1547-1554.

22. Ekmehag, B., Persson, B., Rorsman, P., and Rorsman, H. 1994. Demonstration of voltage-dependent and TTX-sensitive $\mathrm{Na}(+)$-channels in human melanocytes. Pigment Cell Res. 7:333-338.

23. Allen, D.H., Lepple-Wienhues, A., and Cahalan, M.D. 1997. Ion channel phenotype of melanoma cell lines. J. Membr. Biol. 155:27-34.

24. Campbell, D.L., Stamler, J.S., and Strauss, H.C. 1996. Redox modulation of L-type calcium channels in ferret ventricular myocytes. Dual mechanism regulation by nitric oxide and S-nitrosothiols. J. Gen. Physiol. 108:277-293.

25. Lu, Z., et al. 2008. Reactive oxygen species-induced activation of $\mathrm{p} 90$ ribosomal $\mathrm{S} 6$ kinase prolongs cardiac repolarization through inhibiting outward $\mathrm{K}+$ channel activity. Circ. Res. 103:269-278.

26. Wang, W., Ma, J., Zhang, P., and Luo, A. 2007. Redox reaction modulates transient and persistent sodium current during hypoxia in guinea pig ventricular myocytes. Pflugers Arch. 454:461-475.

27. Schmitz, S., Thomas, P.D., Allen, T.M., Poznansky, M.J., and Jimbow, K. 1995. Dual role of melanins and melanin precursors as photoprotective and phototoxic agents: inhibition of ultraviolet radiation-induced lipid peroxidation. Photochem. Photobiol. 61:650-655.

28. Chakraborty, A.K., et al. 1996. Polymerization of 5,6-dihydroxyindole-2-carboxylic acid to melanin by the pmel 17/silver locus protein. Eur. J. Biochem. 236:180-188

29. Tsukamoto, K., Jackson, I.J., Urabe, K., Montague, P.M., and Hearing, V.J. 1992. A second tyrosinaserelated protein, TRP-2, is a melanogenic enzyme termed DOPAchrome tautomerase. EMBO J. 11:519-526.

30. Salinas, C., García-Borrón, J.C., Solano, F., and Lozano, J.A. 1994. Dopachrome tautomerase decreases the binding of indolic melanogenesis intermediates to proteins. Biochim. Biophys. Acta. 1204:53-60.

31. Mazzulli, J.R., Armakola, M., Dumoulin, M., Parastatidis, I., and Ischiropoulos, H. 2007. Cellular oligomerization of alpha-synuclein is determined by the interaction of oxidized catechols with a Cterminal sequence. J. Biol. Chem. 282:31621-31630.

32. Bush, W.D., and Simon, J.D. 2007. Quantification of $\mathrm{Ca}(2+)$ binding to melanin supports the hypothesis that melanosomes serve a functional role in regulating calcium homeostasis. Pigment Cell Res. 20:134-139.

33. Dudley, S.C., Jr., et al. 2005. Atrial fibrillation increases production of superoxide by the left atrium and left atrial appendage: role of the NADPH and xanthine oxidases. Circulation. 112:1266-1273.

34. Zhao, S., and Overbeek, P.A. 1999. Tyrosinase-related protein 2 promoter targets transgene expression to ocular and neural crest-derived tissues. Dev. Biol. 216:154-163.

35. Epstein, J.A., et al. 2000. Migration of cardiac neural crest cells in Splotch embryos. Development. 127:1869-1878.

36. Jiang, X., Rowitch, D.H., Soriano, P., McMahon, A.P., and Sucov, H.M. 2000. Fate of the mammalian cardiac neural crest. Development. 127:1607-1616.

37. Moretti, A., et al. 2006. Multipotent embryonic isl1+ progenitor cells lead to cardiac, smooth muscle and endothelial cell diversification. Cell. 127:1151-1165.

38. Cable, J., Jackson, I.J., and Steel, K.P. 1995. Mutations at the W locus affect survival of neural crestderived melanocytes in the mouse. Mech. Dev. 50:139-150.
39. Breathnach, A.S. 1988. Extra-cutaneous melanin. Pigment Cell Res. 1:234-237.

40. Engleka, K.A., et al. 2005. Insertion of Cre into the Pax3 locus creates a new allele of Splotch and identifies unexpected Pax3 derivatives. Dev. Biol. 280:396-406.

41. Soriano, P. 1999. Generalized lacZ expression with the ROSA26 Cre reporter strain. Nat. Genet. 21:70-71.

42. Van Gelder, R.N., et al. 1990. Amplified RNA synthesized from limited quantities of heterogeneous cDNA. Proc. Natl. Acad. Sci. U. S. A. 87:1663-1667.

43. Guyonneau, L., Rossier, A., Richard, C., Hummler, E., and Beermann, F. 2002. Expression of Cre recombinase in pigment cells. Pigment Cell Res. 15:305-309.

44. Chabot, B., Stephenson, D.A., Chapman, V.M., Besmer, P., and Bernstein, A. 1988. The protooncogene c-kit encoding a transmembrane tyrosine kinase receptor maps to the mouse W locus. Nature. 335:88-89.

45. Steel, K.P., Davidson, D.R., and Jackson, I.J. 1992. TRP-2/DT, a new early melanoblast marker, shows that steel growth factor (c-kit ligand) is a survival factor. Development. 115:1111-1119.

46. Zimmermann, M., and Kalusche, D. 2001. Fluctuation in autonomic tone is a major determinant of sustained atrial arrhythmias in patients with focal ectopy originating from the pulmonary veins. J. Cardiovasc. Electrophysiol. 12:285-291.

47. Bettoni, M., and Zimmermann, M. 2002. Autonomic tone variations before the onset of paroxysmal atrial fibrillation. Circulation. 105:2753-2759.

48. Dimmer, C., et al. 1998. Variations of autonomic tone preceding onset of atrial fibrillation after coronary artery bypass grafting. Am. J. Cardiol. 82:22-25.

49. Grando, S.A., Pittelkow, M.R., and Schallreuter, K.U. 2006. Adrenergic and cholinergic control in the biology of epdermis: physiology and clincal significance. J. Invest. Dermatol. 126:1948-1965.

50. Wakimoto, H., et al. 2001. Induction of atrial tachycardia and fibrillation in the mouse heart. Cardiovasc. Res. 50:463-473.

51. Hamill, O.P., Marty, A., Neher, E., Sakmann, B., and Sigworth, F.J. 1981. Improved patch-clamp techniques for high-resolution current recording from cells and cell-free membrane patches. Pflugers Arch. 391:85-100.

52. Bassani, R.A., Altamirano, J., Puglisi, J.L., and Bers, D.M. 2004. Action potential duration determines sarcoplasmic reticulum Ca2+ reloading in mammalian ventricular myocytes. J. Physiol. 559:593-609.

53. Coppen, S.R., Severs, N.J., and Gourdie, R.G. 1999. Connexin45 (alpha 6) expression delineates an extended conduction system in the embryonic and mature rodent heart. Dev. Genet. 24:82-90.

54. Newton, R.A., Cook, A.L., Roberts, D.W., Leonard, J.H., and Strum, R.A. 2007. Post-transcriptional regulation of melanin biosynthetc enzymes by cAMP and resveratrol in human melanaocytes. J. Invest. Dermatol. 127:2216-2227.

55. Kistler, P.M., et al. 2006. P-wave morphology in focal atrial tachycardia: development of an algorithm to predict the anatomic site of origin. J. Am. Coll. Cardiol. 48:1010-1017.

56. Hillock, R.J., et al. 2007. Multiple focal atrial tachycardias in a healthy adult population: characterization and description of successful radiofrequency ablation. Heart Rhythm. 4:435-438.

57. Mackenzie, M.A., Jordan, S.A., Budd, P.S., and Jackson, I.J. 1997. Activation of the receptor tyrosine kinase kit is required for the proliferation of melanoblasts in the mouse embryo. Dev. Biol. 192:99-107.

58. Novak, A., Guo, C., Yang, W., Nagy, A., and Lobe, G.C. 2000. Z/EG, a double reporter mouse line that expresses enhanced green fluorescent protein upon 
cre-mediated excision. Genesis. 28:147-155.

59. Brown, C.B., et al. 2001. PlexinA2 and semaphorin signaling during cardiac neural crest development. Development. 128:3071-3080.

60. Ismat, F.A., et al. 2005. Homeobox protein Hop functions in the adult cardiac conduction system. Circ. Res. 96:898-903.

61. Wawersik, S., and Epstein, J.A. 2000. Gene expression analysis by in situ hybridization: Radioactive probes. Methods Mol. Biol. 137:87-96.

62. Patel, V.V., et al. 2003. Electrophysiologic characterization and postnatal development of ventricular pre-excitation in a mouse model of cardiac hypertrophy and Wolff-Parkinson-White syndrome.
J. Am. Coll. Cardiol. 42:942-951.

63. Li, J., et al. 2005. Cardiac-specific loss of N-cadherin leads to alteration in connexins with conduction slowing and arrhythmogenesis. Circ. Res. 97:474-481.

64. Liu, F., et al. 2008. Histone-deacetylase inhibition reverses atrial arrhythmia inducibility and fibrosis in cardiac hypertrophy independent of angiotensin. J. Mol. Cell. Cardiol. 45:715-723.

65. Freshney, R.I. 2005. Culture of animal cells: a manual of basic technique. Wiley-Liss. New York, New York, USA. 672 pp.

66. Madesh, M., et al. 2005. Selective role for superoxide in InsP3 receptor-mediated mitochondrial dysfunction and endothelial apoptosis. J. Cell Biol. 170:1079-1090.

67. Byrne, C., and Fuchs, E. 1993. Probing keratinocyte and differentiation specificity of the human $\mathrm{K} 5$ promoter in vitro and in transgenic mice. Mol. Cell. Biol. 13:3176-3190.

68. Bonnerot, C., Rocancourt, D., Briand, P., Grimber, G., and Nicolas, J.F. 1987. A beta-galactosidase hybrid protein targeted to nuclei as a marker for developmental studies. Proc. Natl. Acad. Sci. U. S. A. 84:6795-6799.

69. Lo, C.W., and Gilula, N.B. 1979. Gap junctional communication in the post-implantation mouse embryo. Cell. 18:411-422. 